\title{
Minimally invasive cell-seeded biomaterial systems for injectable/epicardial implantation in ischemic heart disease
}

This article was published in the following Dove Press journal:

International Journal of Nanomedicine

5 December 2012

Number of times this article has been viewed

\author{
Rajeswari Ravichandran ${ }^{1,2}$ \\ Jayarama Reddy Venugopal' \\ Subramanian Sundarrajan ${ }^{1,2}$ \\ Shayanti Mukherjee' \\ Seeram Ramakrishna ${ }^{1,2}$ \\ 'Healthcare and Energy Materials \\ Laboratory, ${ }^{2}$ Department of \\ Mechanical Engineering, National \\ University of Singapore, Singapore
}

Correspondence: Jayarama Venugopal/ Seeram Ramakrishna

Centre for Nanofibers and

Nanotechnology, Faculty of Engineering,

National University of Singapore,

Block E3, 05-12, 2 Engineering Drive 3,

Singapore 117576

Tel +6565164272

Fax +6567730339

Email nnijrv@nus.edu.sg/

seeram@nus.edu.sg

\begin{abstract}
Myocardial infarction (MI) is characterized by heart-wall thinning, myocyte slippage, and ventricular dilation. The injury to the heart-wall muscle after MI is permanent, as after an abundant cell loss the myocardial tissue lacks the intrinsic capability to regenerate. New therapeutics are required for functional improvement and regeneration of the infarcted myocardium, to overcome harmful diagnosis of patients with heart failure, and to overcome the shortage of heart donors. In the past few years, myocardial tissue engineering has emerged as a new and ambitious approach for treating MI. Several left ventricular assist devices and epicardial patches have been developed for MI. These devices and acellular/cellular cardiac patches are employed surgically and sutured to the epicardial surface of the heart, limiting the region of therapeutic benefit. An injectable system offers the potential benefit of minimally invasive release into the myocardium either to restore the injured extracellular matrix or to act as a scaffold for cell delivery. Furthermore, intramyocardial injection of biomaterials and cells has opened new opportunities to explore and also to augment the potentials of this technique to ease morbidity and mortality rates owing to heart failure. This review summarizes the growing body of literature in the field of myocardial tissue engineering, where biomaterial injection, with or without simultaneous cellular delivery, has been pursued to enhance functional and structural outcomes following MI. Additionally, this review also provides a complete outlook on the tissue-engineering therapies presently being used for myocardial regeneration, as well as some perceptivity into the possible issues that may hinder its progress in the future.

Keywords: cardiac-tissue engineering, injectable system, myocardial infarction, biomaterials
\end{abstract}

\section{Introduction}

Coronary heart disease is the main cause of death in the United States, with an approximated annual cost surpassing $\$ 150$ billion. ${ }^{1}$ Myocardial infarction (MI) results in heart-wall thinning, myocyte slippage, and ventricular dilation. The damage to the heart-wall muscle after MI is permanent, as after a phenomenal cell loss the myocardial tissue lacks the intrinsic capability to regenerate. ${ }^{2} \mathrm{MI}$ is caused when supply of oxygen and nutrients to the cardiac muscle is impaired, usually due to occluded coronary arteries. In addition to life-threatening arrhythmia, damage to muscle tissue in the left ventricle (LV) can cause dysfunction and remodeling in terms of progressive dilation imparting structural changes to the myocardium. As a result, the contractile efficiency of the ventricles is greatly reduced. Although the body compensates for LV remodeling initially, mismatch of the mechanical and electrical impulses of the scar tissue with native myocardium eventually affects 
functioning of the heart, leading to chronic heart failure. Remodeling of the LV is characterized by increased stress on its wall, which can be explained by Laplace's law. Laplace's law explains anatomical design affecting functional aspects in terms of the relationship between stress $(T)$ and pressure difference across the inner and outer wall $(\Delta P)$. If $t$ is the wall thickness, and $R$ is the radius of the wall, stress is mathematically calculated as $T=(R \Delta P) / t$. The mechanical properties of the tissue-engineered scaffolds employed for cardiac regeneration should be such that they have the potential to take the stress off the heart walls. There are presently three biomaterial approaches for the intervention of MI: (1) polymeric left ventricular restraint devices, (2) in vitro-engineered cardiac tissue, which is subsequently implanted in vivo, and (3) injecting cells and/or scaffold into the myocardium to create in situ-engineered cardiac tissue. The critical goal for cardiac tissue engineering (CTE) is to generate biocompatible, nonimmunogenic heart muscles with morphological, mechanical, and functional properties similar to that of the native myocardium. Previous reviews in the field of myocardial regeneration have focused on natural and synthetic scaffolds compared with cell-based therapy alone ${ }^{3}$ and injectable acellular hydrogels for cardiac repair, ${ }^{4}$ and a review by Rane and Christman ${ }^{5}$ focused on the progress made in the field of cardiac biomaterial treatments for MI over a time span of 5 years (2006-2011). A recent review by Nunes et al, focused on the latest advancements in CTE based on the use of adult, induced pluripotent, or embryonic stem cells and various strategies such as direct injection of cells and/or biomaterials. ${ }^{6}$ Another review highlighted the importance of stem cells as promising tools for cell therapy for the regeneration of MI, stressing the importance of pluripotent stem cells and tissue engineering for cardiac applications. ${ }^{7}$ In another study, progress in engineering stem cell-derived cardiac tissues, scaffold-free cell-sheet engineering, application of natural/ synthetic polymers and decellularized organs as engineering constructs, association of cardiac cells through microfabrication methods, and the application of perfusion and mechanical/electrical stimulation in bioreactors were discussed. ${ }^{8}$ The present review attempts to summarize the growing body of literature in the field of CTE, primarily with regard to injectable systems and the importance of nanotopography for myocardial regeneration. Additionally, this review also provides a complete overview of the cell-based and tissue-engineering therapies presently being employed in CTE, as well as some perception into the possible problems that may obstruct its progress in the near future.

\section{Complex architecture of the human myocardium}

Heart muscle is highly vascular and contractile tissue enclosed in a double-walled sac called the pericardium, which protects the heart. The outer wall of the human heart is composed of three layers. The outer layer is called the epicardium, or visceral pericardium - since it is also the inner wall of the pericardium - a muscular myocardium, and an endothelial-lined endocardium. The muscular myocardium consists of cardiac muscle cells called cardiomyocytes and fibroblasts. ${ }^{9-11}$ The myocytes are enclosed within the ECM network produced by cardiac fibroblasts. ${ }^{12}$ Essentially, the cardiac ECM is composed of $80 \%$ and $10 \%$ collagen types I and III, respectively. ${ }^{13}$ Other less abundant matrix molecules are collagen types IV, V, and VI; elastin and laminins are also present in the myocardium. ${ }^{14}$ Differential amounts of coexisting collagens account for altered mechanical properties in different regions within the heart. ${ }^{15}$ During systole, alignment of myocytes is maintained by surrounding collagen that is responsible for transmission of force, although most of the wall stress is borne by myocytes. During diastole, lengthening of myocytes uncoils collagen fibers and suction of blood occurs. Appropriate lengthening protects the myocytes from overstretching, while subsequent shortening causes contraction of heart and ejection of blood. ${ }^{15,16}$ Cardiac muscle tissue is also comprised of elongated cells containing striated fibers, ${ }^{17}$ the tissue being attached by intercalated discs that transmit electrochemical potentials between the cytoplasm of consecutive cells via gap junctions. Gap junctions permit action potentials to spread among cells by depolarizing and repolarizing the heart via sodium/potassium exchange channels. This coordinative motion of ions allows the heart to undergo normal diastolic and systolic functions. Besides, there are specialized tissues present for rhythmically producing electrical signals to the myocardium. Therefore, any engineered heart tissue should form functional and electrical syncytia, withstand diastolic load, develop systolic force, and contain a blood-supply system. ${ }^{18,19}$ Precisely how the design of the myocardium relates to heart function has been described by TorrentGuasp et al. ${ }^{20}$ As shown in Figure $1,{ }^{20}$ the heart was spatially unfolded by macroscopic dissection, showing a muscular band that starts at the pulmonary artery and ends at the aorta. This band is comprised of a myocardial fold that 


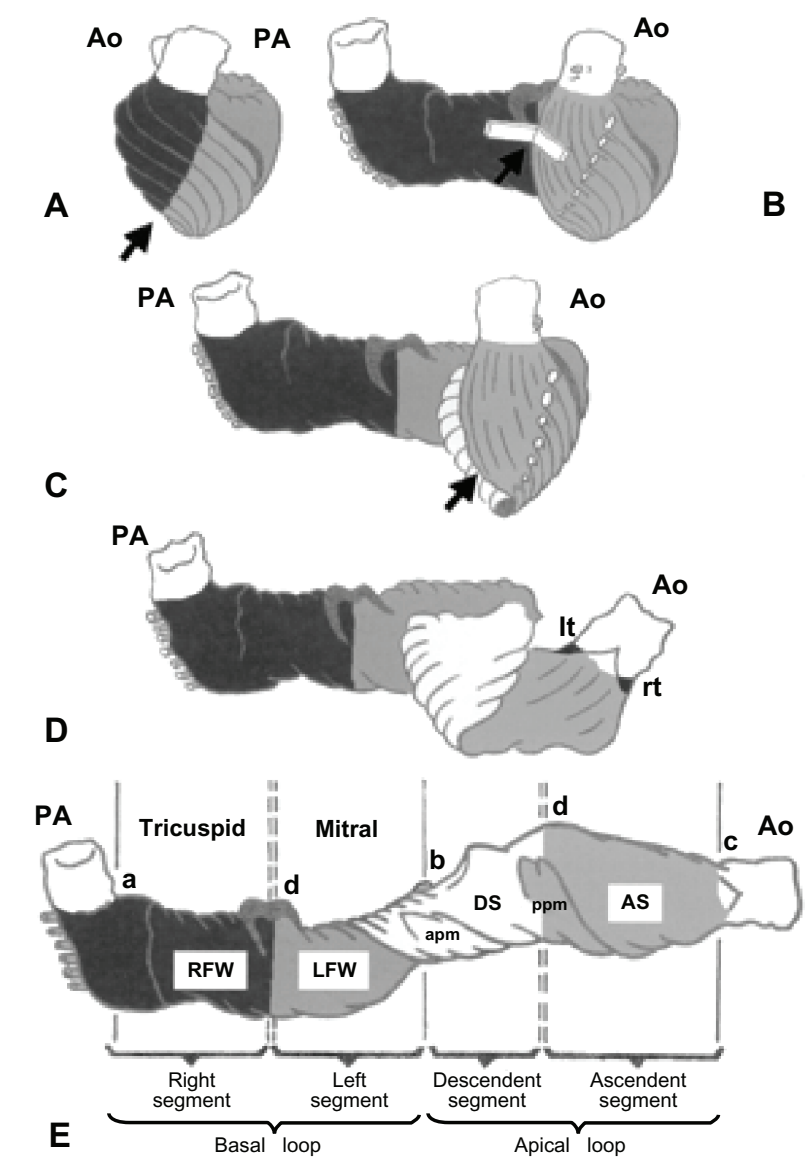

Figure I Schematic representation of the ventricular myocardial band (A-E) for consecutive stages of unwinding. The myocardial band can be divided into four segments (E): RV free wall (RFW, black), LV free wall (LFW, dark gray), descending segment (DS, white), and ascending segment (AS, light gray). The myocardial band extends between the pulmonary artery (PA) and the aorta (Ao). These segments spatially conform to two loops: the basal loop (from A to B), constituted by RFW (black) and LFW (dark gray), and the apical loop (from B to C) formed by the descending segment (DS, white) and the ascending segment (AS, light gray).

Note: Arrows indicate the cleavage plane that provides clues for unwinding the myocardial band.

Abbreviations: apm, anterior papillary muscle; LFW, left ventricular free wall; It, left trigone of the aorta; ppm, posterior papillary muscle; RFW, right ventricular free wall; rt, right trigone of the aorta; RV, right.

Reprinted from J Thorac Cardiovasc Surg. Torrent-Guasp F, Ballester M, Buckberg $\mathrm{GD}$, et al. Spatial orientation of the ventricular muscle band: physiologic contribution and surgical implications. 122:389-392. Copyright (2001) with permission from Elsevier. ${ }^{20}$

divides the heart into two simple loops called the basal and apical loops. It comprises a horizontal or transverse fiber arrangement for the basal loop that surrounds the right and left ventricles, and a change in fiber orientation through a spiral fold in the ventricular band, forming a ventricular helix that contains obliquely arranged fibers. These form descending and ascending segments of the apical loop with an apical vortex. Every pattern reflects the oblique fiber arrangement that employs maximum force during ejection and suction. This complex structure of the human heart focuses the stumbling blocks in CTE for treating MI.
Current treatments employed for $\mathrm{MI}$

The existing treatment alternatives for patients with early stage heart disease are risk-factor modification and medical treatment including beta-adrenergic antagonists, angiotensin-converting enzyme inhibitors, aldosterone antagonists, and late-stage resynchronization therapy. ${ }^{21}$ However, drugs alone cannot control disease progression competently. ${ }^{22}$ As a result, patients depend upon two lifesaving options: heart transplantation or the use of left ventricular assist devices. For final-stage heart failure due to MI, heart transplantation is the gold standard for the survival of patients. There are issues relating to access, with the number of transplants being performed at a declining level in spite of an ascending demand for donor hearts. ${ }^{23} \mathrm{In}$ those with less severe form of disease, valve replacement or repair, interventions such as bypass grafting or angioplasty to reestablish blood flow to compromised myocardium, and pacemakers and defibrillators to regulate heart rhythms are employed. ${ }^{24}$ Despite these treatment options, there is no cure for heart disease, and current therapies simply slow down progression of the disease. Therefore, alternative therapies are required for restoring the infarcted myocardium. The growing field of regenerative therapy and tissue engineering offers promise to restore or replace tissue lost following myocardial infarction. ${ }^{25}$ Table 1 shows the various treatment modalities employed for treatment of MI and their advantages and disadvantages.

\section{$\mathrm{LV}$ restraint devices}

The goal of investigations on LV restraint devices has been to preserve the geometry of the heart by physically wrapping it and therefore preventing the decline of cardiac function that results from the altered spherical structure of post-MI heart. Kelley et $\mathrm{al}^{26}$ demonstrated that poly(propylene) (Marlex)

Table I Different treatment modalities and their advantages and drawbacks

\begin{tabular}{|c|c|c|}
\hline Treatment & Advantages & Drawbacks \\
\hline $\begin{array}{l}\text { Cellular } \\
\text { cardiomyoplasty }\end{array}$ & Noninvasive & Abundant cell loss \\
\hline Injection of biomaterials & $\begin{array}{l}\text { Matrix for homing } \\
\text { autologous } \\
\text { progenitor cells }\end{array}$ & $\begin{array}{l}\text { Immunogenicity, } \\
\text { mismatching of } \\
\text { mechanical properties }\end{array}$ \\
\hline $\begin{array}{l}\text { In situ engineering } \\
\text { (injection of combination } \\
\text { of cells and biomaterials) }\end{array}$ & $\begin{array}{l}\text { Biomaterials support } \\
\text { cell adhesion and } \\
\text { prevent cell loss }\end{array}$ & Infancy stage \\
\hline $\begin{array}{l}\text { Left ventricular } \\
\text { restraint devices }\end{array}$ & No cells & $\begin{array}{l}\text { Involves surgical } \\
\text { procedure }\end{array}$ \\
\hline Tissue engineering & $\begin{array}{l}\text { Ensures cells are } \\
\text { delivered to desired } \\
\text { site with minimal } \\
\text { cell loss }\end{array}$ & $\begin{array}{l}\text { Involves surgical } \\
\text { procedure }\end{array}$ \\
\hline
\end{tabular}


mesh, when sutured onto the myocardium at the MI-induced region, restrained the infarct wall and also preserved both LV geometry and cardiac function, as evidenced by echocardiogram results. Another type of LV restraint consisting of a knitted polyester mesh has been developed by Acorn Cardiovascular (St Paul, MN). In a study by Chaudhry et al, a cardiac support device (CSD) that was fitted around both ventricles using a canine chronic heart failure model was shown to lower myocyte hypertrophy, LV end-diastolic volume, interstitial fibrosis, and increase fractional shortening. ${ }^{27}$ In short, this device principally follows Laplace's law by sharing LV pressure and maintaining normal myocardial wall pressure for preventing LV remodeling. ${ }^{28}$ Acorn's clinical trial involving around 300 patients originally reported that the CSD reduced LV diastolic volume and improved patients' quality of life. ${ }^{25}$ Nevertheless, the implication of the research has been questioned, owing to some contradictory outcomes as to the actual benefit of CSDs in clinical trials, where some measures of cardiac function are ameliorated while other functions are unchanged or deteriorated. ${ }^{29}$ Similarly, the HeartNet device (Paracor Medical, Sunnyvale, CA) is a nitinol mesh that is flexible over a wide range of sizes and can be implanted surgically around the ventricle. The HeartNet device was studied in a pilot trial on 51 patients; however, the results observed were consistent with those observed in the Acorn trial. ${ }^{30}$ Presently, the HeartNet Ventricular Support System is being assessed in the Prospective Evaluation of Elastic Restraint to Lessen the Effects of Heart Failure (PEERLESS-HF) trial, which will determine whether the device is suitable for treating patients with an ejection fraction of $\leq 30 \%$. Even though the initial studies examining epicardial polymeric LV restraints had supporting results, a major drawback with this technique is the surgery required for implantation of the device.

\section{In vitro-engineered myocardial tissue}

An in vitro-engineered cardiac construct is desired to possess certain essential characteristics, such as appropriate physical and mechanical properties, ready adherence, biocompatibility, nonantigenicity, noninvasive applicability, and ability for complete integration with host tissues. Li et $\mathrm{al}^{31}$ examined the transplantation of cells in a biomaterial scaffold for the treatment of MI. They demonstrated the survival of fetal cardiomyocytes on a biodegradable gelatin mesh in vitro and implanted onto the myocardial surface in a cryoinjury model; however, the cell-seeded gelatin grafts did not induce functional improvement of cardiac tissue. Subsequently, Leor et $\mathrm{al}^{32}$ demonstrated both survival and maintenance of cardiac function with fetal cardiomyocytes seeded onto an alginate scaffold, which was later implanted in a rat MI model. In another study, embryonic stem cells were mixed with type I collagen and implanted into the infarct wall by surgically creating an intramural pouch in a rat heterotopic heart-transplant model. ${ }^{33}$ The seeded cells formed viable grafts that improved fractional shortening and prevented infarct-wall thinning compared to animals that received either the scaffold without cells or treatment. Zimmermann et $\mathrm{al}^{34}$ created engineered heart tissue (EHT) by mixing cardiac myocytes isolated from neonatal Fischer 344 rats with liquid type I collagen, Matrigel, and serum-containing culture medium. EHT was made in a circular shape to fit around the circumference of hearts from syngeneic rats. After 12 days in culture, EHT was implanted on uninjured hearts. After fourteen days of implantation, EHT was completely vascularized and retained a well-organized heart muscle structure, evidenced by immunocytochemistry. However the study had drawbacks pertaining to the need for continuous administration of immunosuppressive drugs. This is because generally synthetic constructs do not allow normal cellular remodeling and may trigger immune response that may limit graft-host integration. These studies have involved scaffoldfree or natural matrices for CTE, such as collagen type I and III, the major constituents of the native myocardial matrix. Studies have reported that scaffold-free human myocardial scaffolds, consisting of cardiomyocytes and the matrix to secrete, initially survive poorly after transplantation, but upon inclusion of stromal and endothelial cells enhance survival and vascularization, devoid of any foreign-body response at the graft-host interface. Moreover, it was validated that collagen-based cardiac constructs may provide additional cell-engraftment benefit over cell-injection therapies for infarct repair due to the positioning of the construct over and across an infarct rather than within it, which may increase therapeutic performance, owing to the (1) position that may enhance electrical coupling with intact myocardium on either side of the infarct and (2) separation of the graft from the inflammatory infarct environment. ${ }^{35}$ Recently, Fujimoto et al ${ }^{36}$ demonstrated an in vivo model using a biodegradable porous polyurethane patch sutured to the region of infarcted myocardium. The implanted patch improved cardiac remodeling and contractile function of the heart. Yamada et $\mathrm{al}^{37}$ and Okano et $\mathrm{al}^{38}$ utilized a temperature-responsive polymer, $\operatorname{poly}(N$ isopropylacrylamide), which is hydrophobic and adhesive to cells at $37^{\circ} \mathrm{C}$ but becomes hydrophilic and resistant to cells at $32^{\circ} \mathrm{C}$ due to rapid hydration and swelling. Cardiomyocytes derived from embryonic stem cells (ESCs) were cultured with liquid collagen type I and Matrigel to construct engineered 
cardiac tissue.$^{39}$ After 7 days of in vitro loading, the constructs could beat synchronously and react to physical/pharmaceutical stimulation. Similarly, rat cardiomyocytes cultured on a poly $(N$-isopropylacrylamide) sheet showed that the polymer caused the cell layers to detach when the temperature was reduced, thereby releasing cardiac myocyte sheets from the dishes without enzymatic or ethylenediaminetetraacetic acid treatment. Six months later, the researchers also observed these patches were beating and had been infiltrated by blood vessels. ${ }^{40}$ Zhang et a ${ }^{41}$ used a mixture of collagen, Matrigel, and cell-culture medium to deliver cardiomyocytes similar to Zimmermann et a ${ }^{18,19,34}$ in vitro, and reported conserved LV geometry and heart function. Implantation of engineered neonatal cardiomyocyte sheets to the MI region showed integration with infarcted myocardium and ameliorated cardiac function. Moreover, cultured cardiac cell sheets expressed angiogenesisrelated genes, migrated to connect with the host vasculature, and formed endothelial cell networks after transplantation. ${ }^{42}$ Recent studies observed poly(glycerol sebacate) (PGS) to be a suitable elastomer for engineering cardiac myocardium. ${ }^{43,44}$ It is a biodegradable, synthetic, and biocompatible polymer and exhibits elastomer-like mechanical behavior, ${ }^{45}$ showing a wide range of stiffness values ( $10 \mathrm{kPa}$ to $1.2 \mathrm{MPa}$ ) that could be tailored to be either softer or stiffer than the heart muscles. ${ }^{46}$ Ravichandran et $\mathrm{a}^{47}$ fabricated PGS/fibrinogen core/shell fibers for culturing cardiomyocytes that showed enhanced expression of cardiac-specific marker proteins like actinin, troponin, and myosin heavy-chain and gap junction protein connexin- 43 compared to tissue culture plate and fibrinogen nanofibers, as shown in Figure 2, indicating that these core/shell fibers may prove to be suitable biomaterial for the treatment of MI. They attributed enhanced survival of cardiomyocytes on these scaffolds to the ECM-mimicking nanofibrous architecture and the favorable elastic property provided by $\mathrm{PGS} .{ }^{47} \mathrm{In}$ a similar
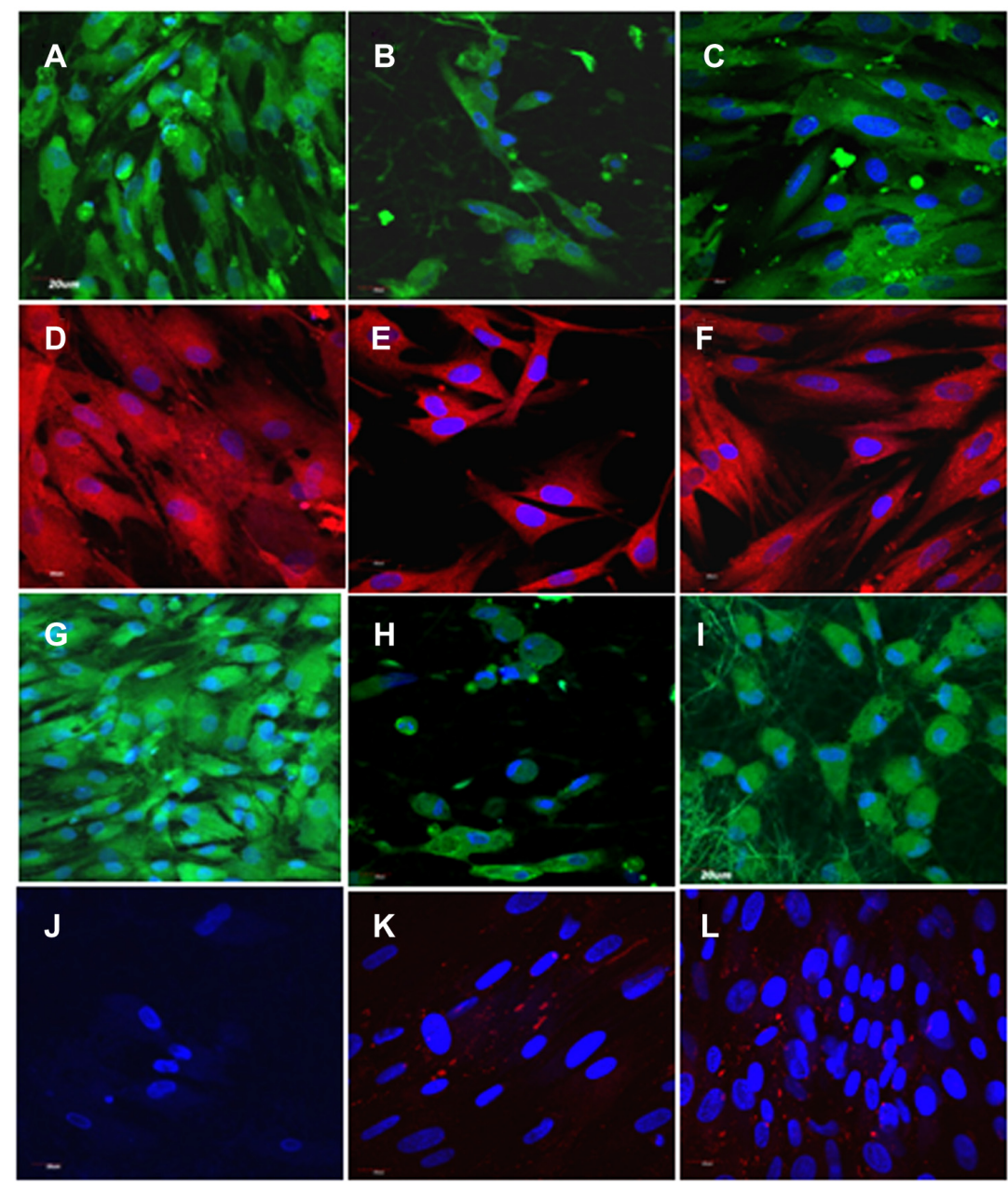

Figure 2 Immunocytochemical analysis for the expression of cardiac marker protein $\alpha$-actinin (A-C), $\beta$-myosin heavy chain (D-F), troponin (G-I), connexin 43 (J-L) on tricalcium phosphate (A, D, G and J) and fibrinogen nanofibers (B, E, $\mathbf{H}$ and $\mathbf{K})$ and poly(glycerol sebacate)/fibrinogen core/shell fibers (C, F, I and $\mathbf{L})$ at $60 \times$ magnification. Note: Nucleus stained with DAPI (4',6-diamidino-2-phenylindole).

Reprinted from Int J Cardiol. Ravichandran R, Venugopal JR, Sundarrajan S, Mukherjee S, Sridhar R, Ramakrishna S. Expression of cardiac proteins in neonatal cardiomyocytes on PGS/fibrinogen core/shell substrate for cardiac tissue engineering. Copyright 20I2, with permission from Elsevier. ${ }^{47}$ 
study, hydrophilic, biocompatible nanofibrous scaffolds made of poly(L-lactic acid)-co-poly( $\varepsilon$-caprolactone)/collagen blend, fabricated by electrospinning, were reported to provide enhanced attachment and growth of adult cardiac cells favoring native myocardium-like alignment of cardiac cells for regeneration of infarcted myocardium. ${ }^{48}$ However, even with all the efforts invested, the in vitro approach for CTE followed by transplantation of biomaterial in vivo has shown only partial success. After transplantation, adequate perfusion, rapid vascularization, cell survival, integration, and function of the engineered cardiac patch remain vital steps in the translation of in vitro cardiac patches into effective clinical tools.

\section{Limitations}

Although these studies share the desire of regenerating sizable constructs using an in vitro approach, the present thickness of $0.5 \mathrm{~mm}$ is improbable to produce any significant changes in human myocardium, which is larger than rat myocardium. Therefore, developing an in vitro-engineered cardiac construct for humans is currently a major obstacle. Furthermore, the constructs do not possess similar anisotropic and nanofibrous structural properties to that of native ECM of myocardium. While acellular and cellular cardiac patches are applied surgically to epicardial heart surface, injectable materials offer the benefit of minimally invasive delivery into the myocardium either to act as a scaffold for cell delivery or to replace the damaged matrix. Additionally, patch materials are sutured to the epicardial heart surface, limiting the therapeutic benefit.
Hence, unlike the patch materials, an injectable system offers an advantageous solution for the regeneration of the infarcted myocardium noninvasively.

\section{Injectables}

An injectable material system offers an exclusive solution for replacing the injured myocardial ECM and delivering cells directly to the region of infarction while providing prospective minimally invasive delivery. The ideal injectable material would be one that mimics the native cardiac ECM environment and meets the clinical requirement of minimally invasive catheter delivery. For tissue engineering, it is important that a material is biocompatible and provides the suitable cell-biomaterial interactions for cell adhesion, proliferation, differentiation, and maturation. ${ }^{49-51}$ Electrospinning is a versatile technique for producing electrospun nanofibers that are capable of mimicking ECM architecture in vitro. A recent study by our group hypothesized that the injection of cells along with short PGS fibers would increase cell-transplant retention and survival within the infarct, compared to the standard cell-injection system. It was reported that electrospun short PGS nanofibers provide the desired nanostructures for tissue-engineering applications, as well as lend themselves to injectable delivery, as shown in Figure 3. With this approach, cells would remain adhered to the nanofibrous injectable material, preventing cell loss and providing a more site-directed cardiac repair mechanism. ${ }^{52}$ Thus, injectable biomaterials should provide biomimetic ECM architecture and meet design necessities

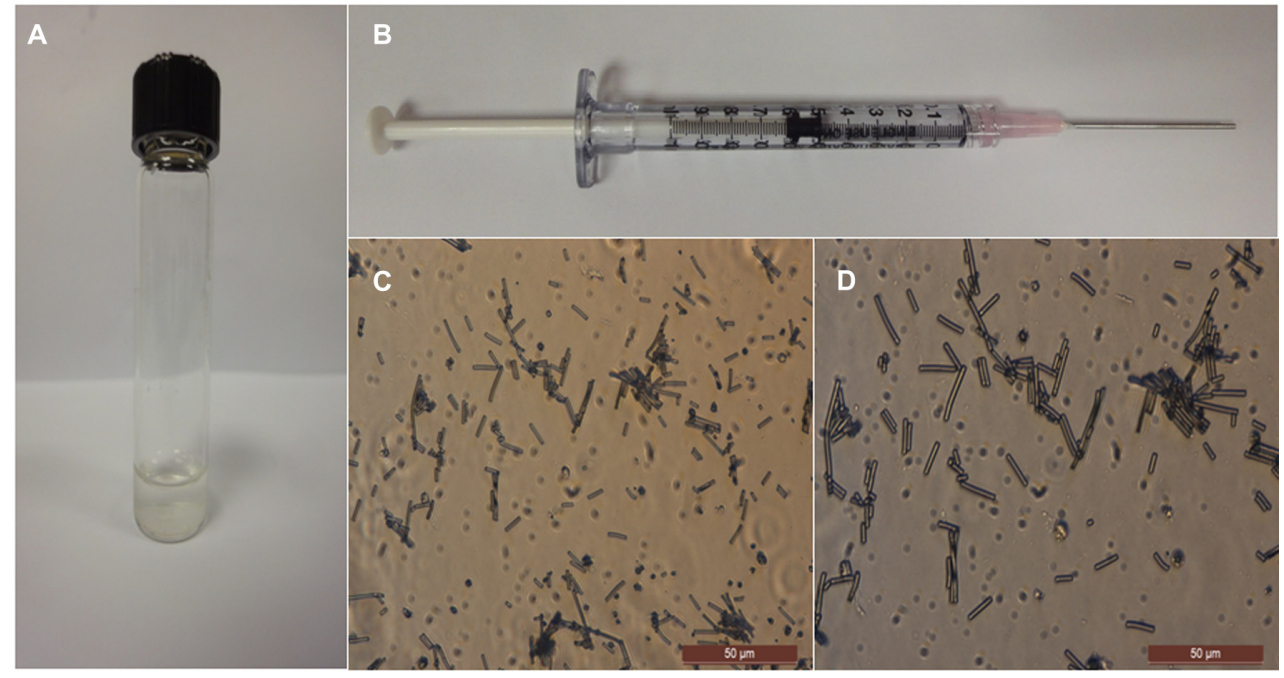

Figure 3 (A) The homogeneous mixture of poly(glycerol sebacate) (PGS) fibers suspended in phosphate-buffered saline solution after stirring for 2 hours with a magnetic stirrer at $37^{\circ} \mathrm{C}$. (B) The PGS fibers loaded in a I $\mathrm{mL}$ syringe prepared for the injectable system. (C) The morphology of the PGS short fibers is retained after passing through the $18 \mathrm{G}$ needle, at $40 \times$ magnification. (D) The morphology of the PGS short fibers after passing through the $18 \mathrm{G}$ needle, at $60 \times$ magnification. Reprinted with permission Nanotechnology. Ravichandran R, Venugopal JR, Sundarrajan S, Mukherjee S, Sridhar R, Ramakrishna S. Minimally invasive injectable short nanofibers of poly(glycerol sebacate) for cardiac tissue engineering. Copyright 2012 IOP Publishing. ${ }^{52}$ 
for coronary or endocardial catheter delivery and must have good gelation properties and kinetics to remain in liquid state within the catheter while allowing the formation of a solid gel within the myocardium.

\section{Injecting cells}

Researchers have over the past decade looked into the possibility of cell transplantation for cardiac repairs. ${ }^{53}$ Several cell types have been considered for such therapies, including skeletal myoblasts, ${ }^{54}$ bone marrow-derived hematopoietic stem cells, ${ }^{55}$ mesenchymal stem cells, ${ }^{56}$ intrinsic cardiac stem cells (CSCs), ${ }^{57} \mathrm{ESCs},{ }^{58}$ and induced pluripotent stem (iPS) cells. ${ }^{59}$ Cell transplantation may be accomplished in one of the following ways: (1) transplanting cells through transepicardial, intracoronary or transendocardial delivery; (2) mobilizing resident stem cells to the injured site using cytokines, such as granulocyte colony-stimulating factor and stem cell factor; or (3) treatment with growth factors, such as insulin-like and hepatocyte growth factors, to induce differentiation of cardiac progenitor cells into cardiomyocytes. ${ }^{60}$

\section{Approaches of stem cell delivery} to the damaged heart

Modes of stem cell delivery into the infarcted site include: (1) intravenous injection, ${ }^{61}(2)$ infusion into coronary arteries, ${ }^{62}$ and (3) direct endomyocardial injection. ${ }^{63}$ For instance, with intravenous injection, it has not been ascertained which elements affect the number of stem cells that home on the heart upon circulation. Intracoronary infusion extends the benefits of directed local delivery, increasing the amount of cells that reach the target tissue compared to the systemic intravenous route. ${ }^{63}$ These methods, however, presume that blood flow of patients after a heart attack is normal. Surgically aided stem cell deliveries are also possible, but depend upon identification of the infarcted area and viable neighboring tissue. A balloon catheter to deliver the stem cells into the infarcted zone through heart vessels after percutaneous transluminal coronary angioplasty has been demonstrated. ${ }^{64}$ Recently, this technique for cell injection has been used for the regeneration of myocardium. ${ }^{65}$ This intravascular delivery was based on the migratory properties of a few cells that retain their power to cross the basal lamina. This approach should be feasible for mononuclear bone marrow cells (BMCs) alone (mean diameter very small $[10-12 \mu \mathrm{m}])$, since intracoronary delivery of skeletal myoblasts and bone marrow mesenchymal stem cells could cause microemboli formation. ${ }^{66}$ Another approach was to deliver stem cells into the systemic vasculature system so that the stem cells home to the site of infarcted myocardium.
The site of circulatory system introduction includes intracoronary and intravenous injection, retrograde venous infusion, and intra-aortic root administration. A drawback of these methodologies is that they have the possibility to cause embolization if the stem cells are very big or clump into aggregates when huge quantities of cells are infused. ${ }^{67}$ Nevertheless, the success of postischemic intramyocardial delivery of cells seems to be hampered by limited cell survival in the ischemic area ${ }^{68}$ and low cell retention. ${ }^{69}$ The infarcted myocardium is a harsh hypoxic environment that is not suitable for cell survival and regeneration. Also, mechanical loss and vascular washout may account for a large amount of cell loss upon intramyocardial injection. ${ }^{70}$

\section{Stem cells}

Stem cells are the optimum source for tissue regeneration and also have the following advantages: (1) capacity for self-replication throughout life, (2) they are clonogenic, and hence each cell can form a colony in which all the cells are derived from a single cell having identical genetic makeup, and (3) they are able to differentiate into one or more specialized cell types. Expansion of stem cells can be directed to differentiate into cardiomyogenic lineage. ${ }^{71-73}$ Therefore, stem cell administration for cardiac regeneration has been under intensive research during the last decade. There are somatic stem cells and ESCs. Somatic stem cells are isolated from adult somatic tissue, such as bone marrow, adipose tissue, umbilical cord blood, peripheral blood, and skeletal muscle. ESCs are derived from embryo at the blastocyst stage and can form completely functional differentiated cells, as well as cardiomyocytes. Stem cellbased therapy for myocardial regeneration was initially based on the assumption that the injected stem cells would differentiate into cardiomyocytes, integrate with the native myocardium, and favor the regeneration of infarcted heart. In vivo studies have showed that stem cell injection attenuated LV dilatation, decreased scar-tissue formation, and improved contractile function. ${ }^{74-76}$ Moreover, studies have also recommended that the beneficial effects of stem cell injection were due to the paracrine action of the injected cells. Bone marrow stem cells have the capability to produce angiogenic growth factors such as vascular endothelial growth factor (VEGF) and platelet-derived growth factor, and antiapoptotic factors such as insulin-like growth factor (IGF-1) and hepatocyte growth factor. ${ }^{77,78}$ This capacity is improved further under a hypoxia environment in the infarcted region, thereby promoting both angiogenesis and cardiomyocyte survival. ${ }^{79,80}$ 


\section{Bone marrow cells}

Bone marrow stem cells are primitive cells in the marrow and can be separated as: (1) bone marrow-derived mesenchymal stem cells (MSCs) and (2) hematopoietic stem cells (HSCs). Thompson et $\mathrm{al}^{81}$ reported the introduction of $\mathrm{BMCs}$ in collagen into the myocardium via catheter; however, no conclusive results could be derived from this study as the injection was done in uninjured hearts, and comparison with cell injection in a liquid solution was not performed. Orlic et $a l^{82}$ reported that a subpopulation of BMCs was capable of myocardial generation in mice. Kocher et $\mathrm{al}^{75}$ found that intravenous injection of $2.0 \times 10^{6}$ human BMCs to the infarcted heart of rats caused considerable increase in neovascularization of postinfarcted myocardium, reduction in cardiomyocyte cell death, and LV remodeling. The ability of BMCs to heal an infarcted myocardium by inducing vasculogenesis and thereby improving heart viability and restoration of cardiac function has promoted the studies from in vivo models to clinical trials. ${ }^{83}$ Intracoronary injection of autologous mononuclear BMCs in patients with acute MI causes a short-term inflammatory response that reduces after 3 months, as influenced by the circulating levels of certain inflammation markers, proposing a suitable window for stem cell transplantation in MI. ${ }^{84}$ Strauer et $\mathrm{al}^{64}$ transplanted BMCs directly into the infarcted zone of the myocardium by a balloon catheter placed within the infarct-related artery. Intracoronary cell transplantation via balloon catheter was performed, using six to seven fractional high-pressure infusions of 2-3 mL cell suspension, each of which contained $1.5-4 \times 10^{6}$ mononuclear cells. The results of the group with cell therapy showed considerable improvement in LV function. Presently, results of three medium-sized clinical trials (100-200 patients) show a varying and moderate healing function of autologous bone marrow stem cells in cardiac function. ${ }^{85,86}$ The application of BMCs for CTE is still in its preliminary stage, as optimum cell source, mode of injection, dose, and timing require optimization. However, the application of bone marrow-derived stem cells is limited by the acquisition of an adequate number of autologous cells from a patient with MI in time in order to prevent postinfarction.

\section{Bone marrow derived mesenchymal stem cells}

Chen et $\mathrm{al}^{87}$ reported substantial improvement in global and LV function after intracoronary transplantation of autologous bone marrow MSCs in patients with acute MI. Nagaya et al ${ }^{88}$ showed that transplanted MSCs expressed cardiac and endothelial cell markers within infarcted sites of rat. The results support the concept that stem cell therapy ameliorates cardiac function after acute MI through enhanced angiogenesis and myogenesis in the ischemic myocardium. There is a growing body of literature signifying the advantageous effect of bone marrow MSCs on myocardial function and remodeling via indirect paracrine signaling that induce cell proliferation and migration and stimulate angiogenesis rather than induction of physiologically significant regeneration of contractile myocardium. ${ }^{89}$ MSCs secrete a variety of bioactive molecules and mediators that promote tissue repair. ${ }^{90}$ MSCs also secrete large amounts of angiogenic and antiapoptotic factors in vitro including fibroblast growth factor (FGF), VEGF, basic transforming growth factor, hepatocyte growth factor, and adrenomedullin (an antiapoptotic peptide). ${ }^{90}$ Additionally, MSCs produce IGF-1, which is a mediator for myocardial growth and placental growth factor, which has an effect on angiogenesis and monocyte recruitment. Further, Tang et $\mathrm{al}^{91}$ also observed that expression of angiogenic factors, including VEGF, FGF, and stem cellhoming factor (stromal cell-derived factor-1 $\alpha$ ) increased significantly in the engrafted MSCs after 2 weeks of transplantation into myocardial infarcts in rats. Additionally, echocardiography showed that LV contractility, measured by fractional shortening, was enhanced 8 weeks after implantation. It was proposed that the engrafted MSCs improved cardiac function through paracrine mechanism. Dai et al ${ }^{92}$ examined the long-term effects of MSCs to treat infarcted scars. They found in rat models of MI that the differentiation of transplanted MSCs to cardiomyocytes was incomplete at the end of 6 months. Furthermore, the long-term capability of MSCs to repair the infarcted myocardium was also questioned by this study. ${ }^{92}$

\section{Hematopoietic stem cells}

HSCs are regularly isolated from the bone marrow, peripheral blood, and umbilical cord based on CD34 and/or CD133 antigens expression. Orlic ${ }^{82}$ injected HSCs into the rat myocardium, which were able to repair $60 \%-70 \%$ of the ischemic damaged tissue by generating endothelial smooth-muscle and cardiomyocytic cells, but cardiomyocyte transdifferentiation was still controversial. ${ }^{54,93}$ In vivo studies showed that HSCs can integrate with the damaged region and occupy up to $68 \%$ of the infarcted site. The transplanted HSCs expressed connexin-43, indicating formation of gap junctions with host myocardium, which is absent in skeletal myoblasts. ${ }^{82}$ Studies in vivo of ischemia and phase I and II clinical trials recommended that delivery of HSCs and circulating endothelial progenitor cells (EPCs) may favor improvement of LV function in ischemic heart patients. ${ }^{83}$ 


\section{Adipose stem cells}

Adipose tissue is an attractive source of MSCs for clinical autologous stem cell therapies and regenerative medicine, as it is copiously available, and more significantly it can be acquired in a less invasive manner and is less expensive than harvest of bone marrow. Adipose-derived stem cells (ASCs) characterize an alternate, easily expandable, and accessible source of stem cells, and like MSCs are multipotent and have been shown to give rise to adipocytes, osteoblasts, chondrocytes, endothelial cells, and cardiomyocytes..$^{94,95}$ The primary benefits of ASCs include the fact that adipose tissue can be readily obtained through regular surgeries coupled with low morbidity in comparison to painful bone marrow aspiration, and the yield of stem cells is roughly 500 -fold greater than that from bone marrow. ${ }^{96,97}$

Planat-Benard and colleagues found that beating cells with cardiomyocyte characteristics could be noticed after ASC culture. The cardiomyocyte phenotype was initially noticed by morphological observation and further confirmed with expression of cardiac-specific marker proteins by immunocytochemistry and ultrastructural analysis, revealing the presence of ventricle and atrial-like cells. Electrophysiological studies on early culture demonstrated pacemaker activity of these cells. ${ }^{94}$ Additionally, the same group showed that adipose lineage cells function as progenitors for endothelial cells. They were reported to take part in vascular-like structure configuration in Matrigel plug and improve neovascularization in ischemic heart tissue. ${ }^{95}$ This opens novel perspectives on angiogenic therapy based on the injection of ASCs for treatment of MI. ${ }^{98}$ Recently, there has been a growing body of literature demonstrating spontaneous differentiation of ASCs into active cardiomyocyte like cells without treatment with chemicals like 5-azacytidine both in in vitro ${ }^{94}$ and animal studies. ${ }^{99}$ Similarly, it was
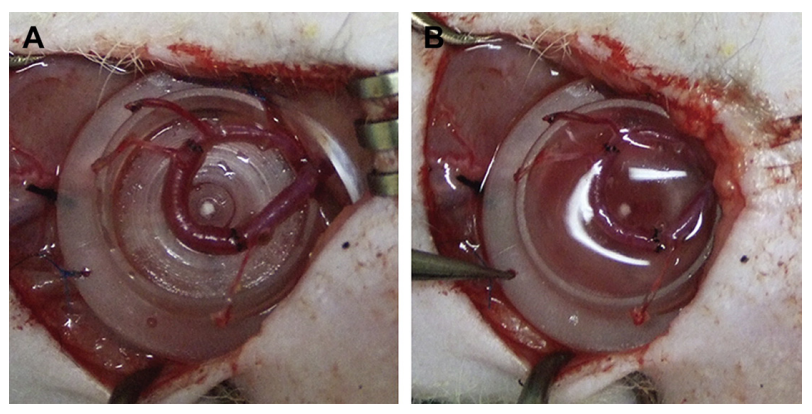

Figure 4 (A) An AV loop was constructed and placed into the tissue engineering chamber in the nude rat groin. (B) Cells (ASC-rCM or ASC or rCM) suspended in Matrigel $^{\mathrm{TM}}$ were seeded around the AV loop.

Reprinted from Biomaterials. Choi YS, Matsuda K, Dusting GJ, Morrison WA, Dilley RJ. Engineering cardiac tissue in vivo from human adipose-derived stem cells. 31:2236-2242. Copyright 2010 with permission from Elsevier. ${ }^{99}$ suggested that even though there was poor engraftment of intramyocardial delivery postinfarction of freshly isolated ASC, they showed good therapeutic effect on heart functionality in rats by means of proangiogenic effect. ${ }^{100} \mathrm{~A}$ later study demonstrated the utilization of a tissue-engineering chamber that incorporates an arteriovenous loop for the generation of human cardiac muscle cells in vivo from ASCs cocultured with rat cardiomyocytes ( $\mathrm{rCMs}$ ) as shown in Figure $4 .{ }^{99}$ After 6 weeks of implantation, the ASC/rCM coimplantation allowed spontaneous differentiation of ASCs into cardiac cells, adipocytes, and smooth-muscle cells in the rat groin. This methodology successfully produced a considerable amount of vascularized human cardiac tissue. Nevertheless, to improve its clinical relevance, it is essential to have a thorough understanding of the mechanisms involved in ASC differentiation to cardiomyogenic lineage, so that autologous ASCs into cardiac tissue can be made without the requirement of $\mathrm{rCM}$ coculture and unwanted differentiation to adipogenic lineage can be avoided for CTE applications.

\section{Cardiac stem cells (CSC)}

CSCs are self-renewing, c-kit-positive, multipotent, and clonogenic cells. They engender myocytes, endothelial cells, and smooth muscle. Although the main role of CSCs is in cardiac homeostasis, they also contribute to normalization of cardiac functioning post-MI. CSCs can also form both myocytes and vasculature in the MI region, favoring restoration of dead tissue. ${ }^{101}$ Beltrami et a ${ }^{57}$ reported the functional regeneration of the infarcted myocardium by injecting $2 \times 10^{5} \mathrm{CSCs}$ into ischemic rat hearts. A recent study by Li et al challenges the present claims about CSC regenerative potential on the infarcted myocardium. ${ }^{102}$ They isolated mice c-kit-positive and Sca-1-negative CSC coexpressing the MSC markers CD106 and CD90. They were then injected into murine infarcted myocardium and their fate analyzed by in vivo bioluminescence imaging, as shown in Figure 5. The results showed acute donor stem cell apoptosis after intramyocardial delivery of cells, and most importantly CSC transplantation was unsuccessful in providing any functional improvement in comparison to infarcted mice injected with saline. In a phase 1 clinical trial (Stem Cell Infusion in Patients with Ischemic Cardiomyopathy [SCIPIO]) of autologous CSCs for the treatment of cardiac failure as a result of ischemic heart disease was performed. The study reported that in 14 CSCtreated patients, intracoronary infusion of autologous CSCs was efficient in improving LV systolic function and reducing infarct size in those patients, compared to seven control 

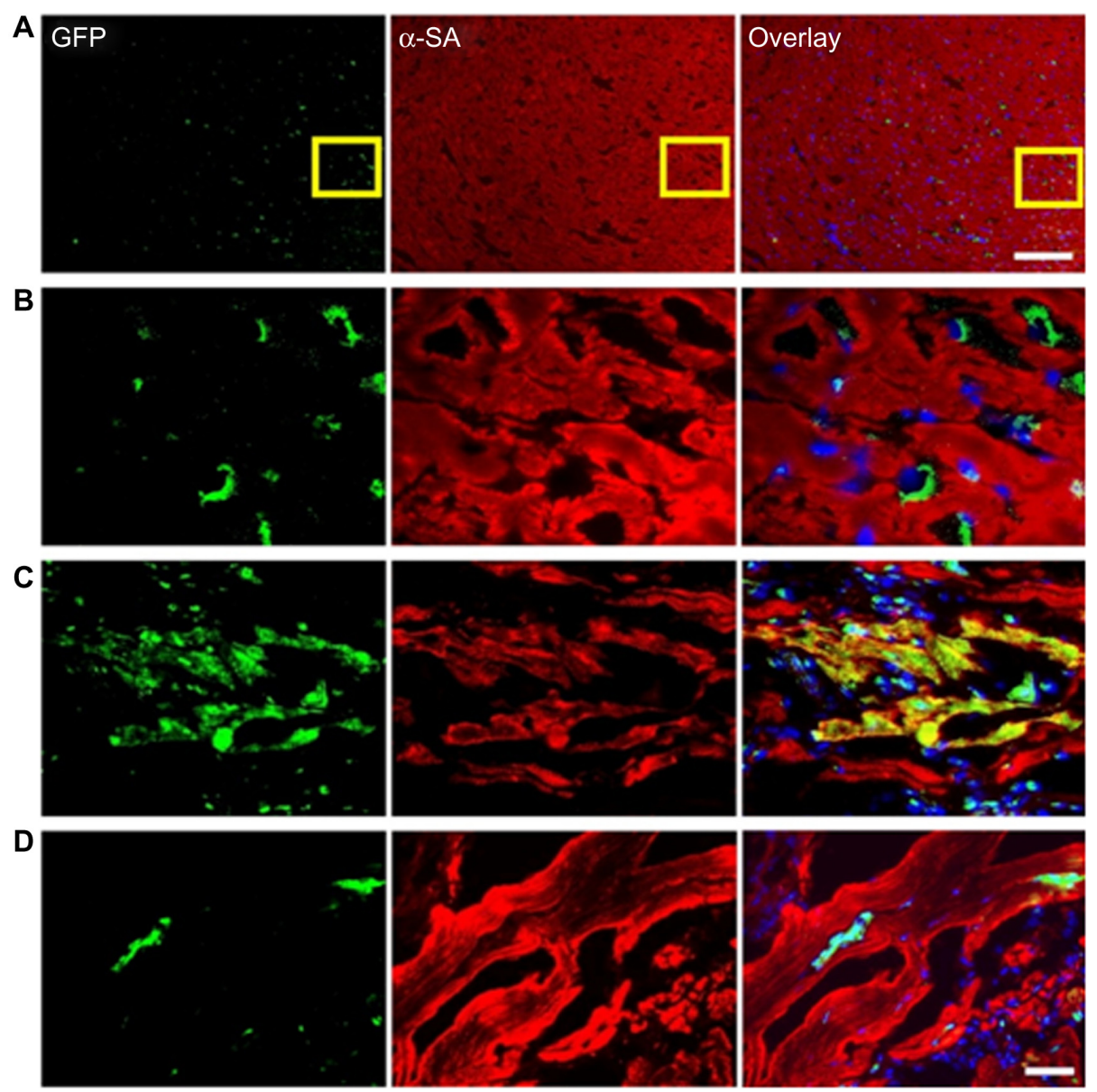

Figure 5 (A-D) Tracking of grafted cardiac stem cells (CSCs) by immunofluorescence. (A and B) CSCs within the recipient myocardium 3 days after injection shown at low and high magnification. (C and D) Transplanted CSCs can differentiate and integrate with host myocardium, as confirmed by green fluorescence protein (GFP) and $\alpha$-sarcomeric actin (SA) double-staining. At day I4, CSCs could differentiate into cardiomyocytes, as confirmed by $\alpha$-SA and GFP double-staining (C). However, this population became significantly decreased when the tissues were examined at day 28 (D), which is also consistent with the decrease in bioluminescence signals over this period. Scale bar $=100 \mu \mathrm{m}(\mathbf{A}), 20 \mu \mathrm{m}(\mathbf{B}-\mathbf{D})$

Reprinted from J Am Coll Cardiol. Li Z, Lee A, Huang M, et al. Imaging survival and function of transplanted cardiac resident stem cells.53:1229-I240. Copyright 2009 with permission from Elsevier. ${ }^{102}$

patients, during the corresponding time interval. ${ }^{103}$ On the whole, these results indicated that future studies focusing on the mechanisms underlying CSC biology and also on ways to exploit these cells for CTE, like harvesting methodologies, are necessary before any therapy employing these cells is incorporated therapeutically.

\section{Embryonic stem cells (ESCs)}

ESCs can be isolated from the inner mass of blastocyst and expanded for an indefinite period in vitro. ${ }^{104}$ ESCs remain pluripotent in an undifferentiated state in culture, and can differentiate into various somatic cell lineages. ${ }^{105}$ Moreover, ESCs have advantages in direct cardiogenic differentiation, ${ }^{106}$ integration with the host heart, and improvement of electrical conduction. ${ }^{107}$ Thus, theoretically ESCs could provide an infinite supply of cardiomyocytes for the regeneration of infarcted myocardium. Application of ESCs to repair cardiac tissues postinjury has been tested in several preclinical studies, with positive results. ${ }^{108}$ The first study using ESCs as a source for cell transplantation into the heart was reported by using genetically selected mouse ESC-derived cardiomyocytes. They demonstrated that the differentiated cells formed myofibrils and gap junctions between neighboring cells and performed synchronous contractile activity in vitro for up to 7 weeks. ${ }^{109}$ Alperin and coworkers have demonstrated successfully that ESC-derived cardiomyocytes on thin polyurethane films generated myocytes that showed fully contractile behavior and few structural properties characteristic of early stage myocytes. They also produced sufficient force to allow for contraction of thin polyurethane films. ${ }^{110}$ Another study showed that in the MI region, grafted ESCs differentiated into cardiomyocytes with functional activity and integrated with surrounding tissue, improving contractile activity. ${ }^{11,112}$ 
Menard et al demonstrated that cardiac-committed mouse ESCs, when transplanted to the infarcted heart of sheep after incubation with bone morphogenetic protein 2 , differentiated to mature cardiomyocytes, and also considerable improvement in cardiac function independent of whether sheep were immunosuppressed or not. ${ }^{113,114}$ Another study showed increased immunogenicity of mouse ESCs upon in vivo differentiation after transplantation into the MI region of allogeneic animals, proving that clinical injection of allogeneic ESCs for the treatment of infarcted myocardium may necessitate immunosuppressive therapy. ${ }^{115}$ This was further confirmed by Nussbaum et al, ${ }^{116}$ who noticed that undifferentiated mouse ESCs constantly formed cardiac teratomas in nude or immunocompetent syngeneic mice, suggesting lack of guided differentiation into cardiac lineage. Thus, the main obstacles that hinder the clinical use of ESCs are immunological rejection and their tendency to form teratomas upon injection in vivo. ${ }^{117}$ Recently, methods to limit teratoma formation have been established that include the genetic selection of differentiated $\mathrm{ESCs}^{118}$ or the differentiation of ESCs in vitro into cardiomyocytes or endothelial cells before transplantation. ${ }^{119}$ However, the clinical relevance of these procedures for cardiac regeneration is still under question.

\section{Induced pluripotent stem cells (iPS)}

Recently, cells with characteristics reminiscent of ESCs were isolated from somatic tissues through nuclear reprogramming via the ectopic expression of genes related to pluripotency. ${ }^{120,121}$ This groundbreaking advance provides a substitute to generate cell lines with cardiomyogenic potential in lieu of embryos. Furthermore, this strategy can be used to develop patientspecific stem cells for probing into the genetics of disease progress, regenerative biology, and drug actions. In general, iPS cells are similar to ESCs in morphology, differentiation capacity, gene-expression profile, and teratoma formation, although there are subtle epigenetic variations related to the reprogramming mechanism. ${ }^{122}$ Studies have shown that human fibroblasts or iPS cells transduced with human stemness factors are capable of differentiation into functional cardiomyocytes. ${ }^{123}$ A study demonstrated that iPS cells, upon transplantation into infarcted myocardium in adults, generated engraft without disrupting the cytoarchitecture in immune-competent recipients. Contradictory to fibroblasts, iPS cells could restore postischemic contractile functionality, electrical stability, and ventricular wall thickness. ${ }^{59}$ In view of the similarity of iPS cells with ESC, the issues that baffle ESC scientists also face iPS scientists. For instance, traditional methodologies of reprogramming using oncogenes and vector incorporation forbid the therapeutic application of iPS cells. Nevertheless, current studies suggest proof of concept for nonvector pluripotent induction. ${ }^{124}$ Nonvector techniques will make iPS cells an attractive viable prospect for CTE.

\section{Cardiomyocytes}

Earlier cell-transplantation studies were centered on using fetal or neonatal rodent cardiomyocytes, as these have the intrinsic structural, electrophysiological, and contractile properties of cardiomyocytes, besides retaining some proliferative potential. One gram of adult myocardium contains approximately 20-40 million myocytes ${ }^{125}$ and MI that induces heart failure leads to a loss of roughly $50 \mathrm{~g}$ of the heart muscle. ${ }^{126}$ To counterbalance such a huge loss, it seems likely that engineered myocardium should not only have the same volume but also contain the same amount of myocytes (1-2 billion/50 g). Both fetal cardiomyocytes ${ }^{127}$ and neonatal cardiomyocytes ${ }^{128}$ have been employed in vivo and have demonstrated improved global ventricular functionality. Soonpaa et al noticed that fetal cardiomyocyte could be transplanted and incorporated within the healthy mouse myocardium, and that the surviving donor cells were aligned with recipient cells and produced cell-to-cell contacts. ${ }^{129}$ Cardiomyocyte transplantation, when applied to smaller infarcts, ${ }^{130}$ has proved effective in the prevention of cardiac dilation and remodeling after infarction. ${ }^{131}$ However, it is proven that cardiomyocytes are predifferentiated cells without the proliferative capacity to regenerate, though a couple of studies in patients who suffered an acute MI suggest that there is a small number of cardiomyocytes capable of entering the cell cycle actively. ${ }^{132,133}$ Although in vivo transplanted cardiomyocytes were found to integrate into the damaged myocardium, ${ }^{127,128}$ the results in a porcine animal model showed that the majority of the transplanted cells were separated from host cardiomyocytes by scar tissue. ${ }^{134}$ This is a severe drawback, as incomplete electrical conduct would lead to fatal arrhythmias. Besides, several queries are still unanswered in terms of using cardiomyocytes to form cardiac tissue. A chief drawback of this approach is the limited proliferation ability of cardiomyocytes. ${ }^{135}$ The low percentage of proliferating cardiomyocytes in addition to the damaged myocardium limits the clinical impact possible in CTE.

\section{Myoblasts}

Muscle-derived stem cells, also known as myoblasts or satellite cells, are precursors rather than stem cells, which usually lie in a dormant state under the basal membrane of skeletal muscle fibers. Upon injury to tissue, these cells 
quickly mobilize, proliferate, and combine, thus regenerating the injured tissue. They have a high proliferation capacity under proper cell-culture conditions, which allows for a substantial scale-up of the initial biopsy, and a high resistance to ischemia, which is likely to enhance cell survival following attachment into poorly vascularized scars. The first studies using skeletal myoblasts (SkMs) were performed by transplantation of SkMs into cryoinjured dog hearts. ${ }^{136}$ Later, functional improvements in myocardium-injured in vivo models by intramyocardial transplantation of SkMs were demonstrated. ${ }^{137}$ Pouly et al ${ }^{138}$ further demonstrated that transplanted myoblasts could embed into a nonischemically diseased myocardium and favor improved LV performance. Tambara et al studied the transplantation of diverse numbers of freshly isolated neonatal SkMs into ischemic regions of Lewis rats and noticed that transplanted SkMs could completely replace the infarcted region when they survived in large numbers within the host. ${ }^{139}$ The valuable results from in vivo experiments triggered therapeutic trials of SkM transplantation in MI patients in 2000. ${ }^{140}$ Even though initial studies using SkMs were promising in treating MI, the final outcome was not as desired, because it was soon recognized that the acquisition of cardiac phenotype by a few engrafted SkMs was a consequence of their combination with host cardiomyocytes and not due to transdifferentiation, as previously assumed. ${ }^{141}$ For instance, it was demonstrated that transplanted myoblasts can differentiate into peculiar hyperexcitable myotubes with a contractile activity completely independent of adjacent cardiomyocytes. ${ }^{142}$ The electrical stimulation of implanted myoblasts may risk arrhythmias. ${ }^{143}$ The study reported that SkMs express considerable amounts of neural cadherin and connexin-43 but downregulation of these proteins as they differentiate into myotubes. The mature skeletal muscle grafts in the injured heart do not express significant amounts of connexin-43 and neural cadherin, and hence could not form detectable electromechanical junctions with host tissue, resulting in arrhythmias.

\section{Endothelial progenitor cells (EPC)}

EPCs are phenotypically and functionally different compared to mature endothelial cells (ECs), but have the potential to differentiate into mature ECs and add to the process of endothelium repair. In a study, the lineage relationship based on the angiogenic function of early EPCs and late-outgrowth endothelial cells (OECs) in the culture was determined. The authors found that human OECs and not EPCs expressed regulatory proteins such as endothelial nitric oxide synthase and caveolin-1. Moreover, OECs showed greater capacity for capillary morphogenesis in both in vitro and in vivo Matrigel models compared to EPCs. The study revealed that OECs possess a more pronounced endothelial phenotype than EPCs and hence exhibit better intrinsic angiogenicity with abundant proliferative potential and may serve to move forward autologous cell-based therapeutic approaches to ischemic cardiovascular disease. ${ }^{144}$ However, optimization of OEC culture is required before these cells may be more acceptably investigated for clinical applications, as their delayed outgrowth from culture may hinder their relevance in the situation of recent ischemia if there is limited time for clinical benefit. EPCs exist in adult bone marrow, cord blood, and peripheral blood circulation. ${ }^{145}$ An earlier report demonstrated that impairment of EPC functions is associated with cardiovascular risk factors such as diabetes mellitus, hypertension, and atherosclerosis. ${ }^{146}$ Hence, EPC injury might induce EC dysfunction, which additionally affects the progression of cardiovascular disease. The transplantation of EPCs might be an appropriate way to treat cardiovascular diseases arising due to injury or dysfunction of ECs. ${ }^{147}$ There is significant evidence that EPCs from patients suffering from cardiovascular risk elements or healthy smokers have a decreased ability for cell proliferation and differentiation. ${ }^{148,149}$ Still, this impaired differentiation or proliferation ability is not present in EPCs from cord blood. Therefore, cord blood-derived EPCs show greater proliferative potential and express telomerase, a functional characteristic of stem cells that is very low or absent in other progenitor cell populations. They also show speedy self-renewal and low cell death; hence, EPCs from umbilical cord blood are rather promising for future CTE applications and stem cell therapies. ${ }^{150}$

\section{Methods to induce cardiogenic differentiation of stem cells in vitro}

Though the differentiability of BM-MSCs into cardiomyocytes and vascular cells in vivo remains uncertain, ${ }^{151,152}$ many studies have suggested the capacity of BM-MSCs to display ex vivo cardiomyogenic commitment upon in vitro chemical treatment with the DNA demethylating agent 5-azacytidine, ${ }^{72,153}$ inclusion of growth factors, ${ }^{154}$ or electrostimulation. ${ }^{155}$ Studies have shown that human MSCs undergo cardiogenic and vascular differentiation in the adult heart. ${ }^{156}$ Tomita et al compared fresh BMCs, cultured BMCs, and 5-aza-induced BMCs, and proved that improved myocardial functionality occurred in the group treated with 5-aza-induced BMCs. The cells were injected into a cryonecrosis-induced scar of the heart, and only 5-azatreated BMCs enhanced the contractile ability of damaged 
heart. ${ }^{157}$ Additionally, treatment of murine MSCs with 5-aza was performed, and they isolated a cardiomyogenic cell line after continuous screening of the spontaneous beating cells. ${ }^{72}$ Another study also showed that bone marrow-derived cells combine in vivo with cardiomyocytes by cell fusion. ${ }^{158}$ This raised the likelihood that cell fusion may favor the ability of transplanted stem cells to adopt the phenotype of the host tissue. It was also found that both differentiation and cell fusion favor the phenotypic changes in human bone marrow-derived multipotent stem cells. ${ }^{159}$ Ravichandran et al reported that the coculture of MSCs with cardiomyocytes, in the ratio of 1:1 (5000:5000 cells/well), promoted the cardiomyogenic differentiation of MSCs on PGS/gelatin core/shell fibers, which was demonstrated by immunocytochemical analysis as indicated in Figure 6. The MSCs' differentiation into cardiomyocytes was attributed to the ECM-mimicking microenvironment provided by the nanofibers, favoring cell fusion and the presence of biomolecules secreted by cardiomyocytes in the cell-culture milieu. ${ }^{44}$
Challenges involved in the injection of cells for cardiac tissue engineering

Preferably, the stem cells employed for CTE should be readily harvestable and available with minimal morbidity. Induction or exacerbation of arrhythmias after the injection of cells is also a chief problem. Moreover, given the high arrhythmogenic potential of the ischemic heart, improper injection of cells might also cause arrhythmias, as in the case of SkMs, due to incomplete differentiation, poor cell coupling, and electrophysiological differences between host and donor cells. ${ }^{21}$ Although clinical trials involving limited numbers of patients have described no harmful arrhythmia after bone marrow mononuclear cells (BMMNC) intramyocardial injection ${ }^{160}$ or MSC-patch epicardial implantation, ${ }^{161}$ prophylactic antiarrhythmic therapies may be desirable before myocardial delivery of new tissue-engineering therapies. Originally, cellular cardiomyoplasty involved injection of cells in saline or media without any scaffold. Even though this method showed promise in
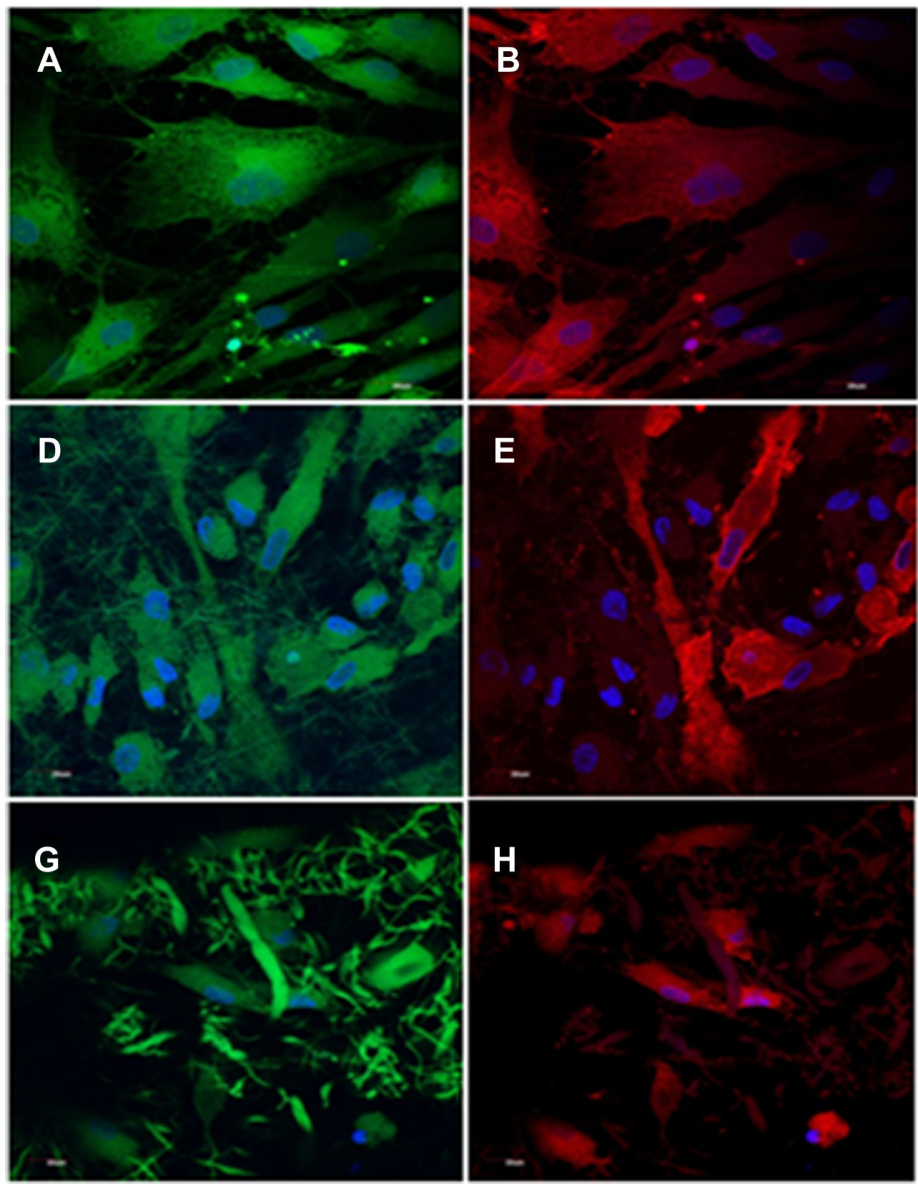
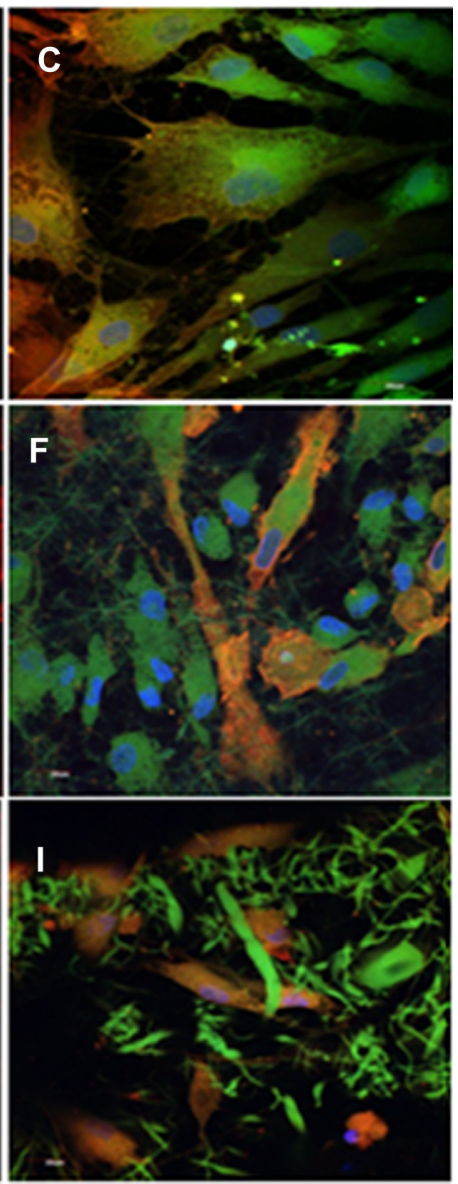

Figure 6 Dual immunocytochemical analysis for the expression of mesenchymal stem cell marker protein CD I05 (A, D and G) and cardiac marker protein actinin $(\mathbf{B}, \mathbf{E}$ and $\mathbf{H})$ in the coculture samples and the merged image showing the dual expression of both $\mathrm{CD} I 05$ and actinin $(\mathbf{C}, \mathbf{F}$ and $\mathbf{I})$; on the tricalcium phosphate (A-C) and gelatin nanofibers (D-F) and poly(glycerol sebacate)/gelatin core/shell fibers (G-I) at 60× magnification.

Note: Nucleus stained with DAPI (4',6-diamidino-2-phenylindole). Reprinted with permission Tissue Eng Part A. Ravichandran R, Venugopal JR, Sundarrajan S, Mukherjee S, Ramakrishna S. Poly(glycerol sebacate)/gelatin core/shell fibrous structure for regeneration of myocardial infarction. Copyright 20 I I Mary Ann Liebert Inc. ${ }^{44}$ 
preclinical and clinical trials, ${ }^{162,163}$ lack of a suitable extracellular milieu for cellular attachment has limited cell adhesion, survival, and integration within the infarct region. ${ }^{164}$ Lately, biomimetic scaffolds have been used as injectable materials, ${ }^{32,165,166}$ referred to as in situ gelling materials, either with or without cells to promote cell survival for CTE. Table 2 shows the different cell types used for cardiac tissue engineering and their advantages and drawbacks.

\section{Injection of biomaterials}

The combination of cells with biomaterial as an injectable material would improve the cell attachment, since the biomaterial and/or cell suspension has higher viscosity than salinebased cell suspension. Moreover, incorporation of biomaterial would reduce apoptosis, as the cells can attach to the biomaterial to reduce cell death. ${ }^{80}$ Lack of an appropriate milieu in infarcted myocardium might be the reason for such stupendous loss of cells and ineffective homing of injected cells. Thus, in order to enhance cell adhesion, proliferation, and differentiation, it is necessary to mimic some of the nanotopography of the natural myocardial ECM. Scaffolds with nanostructured architecture provide larger surface area to adsorb proteins and provide more binding site to cell-membrane receptors, unlike microscale and flat surfaces. ${ }^{167}$ Therefore, injection of biomaterials with or without cells is believed to overcome the aforementioned drawbacks. In addition, the biological properties of the materials also affect the cell-biomaterial interactions. Natural polymers like collagen, gelatin, and alginate have inherent peptide sequences that can be easily recognized by the cell-surface receptors. Hence cell-biomaterial interactions in the case of natural polymers are more predominant, resulting in favorable cell proliferation and differentiation. However, in the case of synthetic polymers like PLLA and PLGA, the polymers are hydrophobic and lack cell-recognition moieties. Thus, in the majority of cases, synthetic polymers are used in combination with a natural polymer or small peptide sequences are added, in order to promote cell-biomaterial interactions for tissue regeneration.

\section{Alginate}

Alginate is a polysaccharide obtained from brown seaweed and has the exceptional ability to undergo phase transition, employing calcium present in the myocardium, upon injection into the LV wall. ${ }^{168}$ It has been FDA-approved for human use as wound-dressing material. ${ }^{169}$ The use of alginate has shown affirmative results in both acute and chronic rat MI models, ${ }^{170}$ besides also being injected with growth factors ${ }^{171}$ or modification with RGD. ${ }^{172}$ Leor et al found that in situ formation of alginate hydrogel when injected via intracoronary injection in a swine model reversed LV remodeling after MI. ${ }^{168}$ In an ongoing clinical trial sponsored by Ikaria and presented by Leor et al, the efficacy of the IK-5001 device, comprising an aqueous mixture of sodium alginate and calcium gluconate, was administered through intracoronary slow bolus injection for the prevention of LV remodeling and congestive heart failure, when administered to patients who had successful percutaneous coronary intervention with stent placement after ST-segment elevation MI. The trial is expected to be completed by November 2012. Landa et al studied the capability of alginate to improve LV remodeling and function upon injection as a bulking agent into the heart muscle. ${ }^{170}$ They compared the results of injecting $150 \mu \mathrm{L}$ of alginate (molecular weight $30 \mathrm{kDa}$ ) solution both 7 days after infarct (recent) and 8 weeks after infarct (old). It was observed that 8 weeks after alginate injection into recent infarcts, the LV geometry improved as witnessed from LV wall thickness and attenuated LV dilation in comparison to the control hearts, which received saline injection. The improvement in old infarcts was comparatively less distinct, indicating the greater difficulty in rescuing a chronically infarcted myocardium. Another possibility is that the injected biomaterial did not improve heart function by inducing regeneration, but by preventing remodeling and deterioration, and hence there was improvement in recent but not old infarct. Others have reported that injection of plain alginate into the myocardium causes increase in capillary and arteriole density and myofibroblast infiltration. ${ }^{171,172}$ They reported that

Table 2 Different types of cells used for cardiac tissue engineering and their advantages and drawbacks

\begin{tabular}{|c|c|c|c|c|c|c|}
\hline Cells & Autologous & $\begin{array}{l}\text { Easily } \\
\text { obtainable }\end{array}$ & $\begin{array}{l}\text { Highly } \\
\text { expandable }\end{array}$ & $\begin{array}{l}\text { Cardiac } \\
\text { myogenesis }\end{array}$ & $\begin{array}{l}\text { Clinical } \\
\text { trials }\end{array}$ & Safety \\
\hline Fetal cardiomyocytes & No & No & No & Yes & No & No \\
\hline Skeletal myoblasts & Yes & Yes & Age-dependent & Debated & Yes & Cause arrhythmias \\
\hline Smooth-muscle cells & Yes & Yes & Yes & No & No & No \\
\hline Fibroblasts & Yes & Yes & Yes & No & No & No \\
\hline Mesenchymal stem cells & Yes & No & Age-dependent & Yes & No & Fibrotic calcification \\
\hline Endothelial progenitor cells & Yes & Yes & Age-dependent & Debated & No & Calcification \\
\hline Embryonic stem cells & No & No & Yes & Yes & No & Teratoma \\
\hline
\end{tabular}


alginate hydrogel injection into the infarct area of rats 5 weeks post-MI showed improved heart function, accompanied by increased arteriole density and capillary formation, while LV function in the control group degenerated. ${ }^{172}$ Even though the direct reason behind the increase in cell population was not thoroughly understood, it may be due to alginate creating a favorable milieu through stress shielding, which increases cell infiltration. Another mode to promote cell infiltration into alginate was the blending of conducting polymer polypyrrole (PPy) with alginate. ${ }^{173}$ Though PPy does not possess good mechanical properties, it may be principally beneficial for cardiac injection, owing to its ability to transmit electrical signals and support endothelial cell growth. ${ }^{174}$ Injection of $0.025 \% \mathrm{w} / \mathrm{v}$ PPy with alginate led to a considerably higher arteriole density than alginate injection alone. The enhanced cell adhesion to PPy, both in vitro and in vivo, was reported to be because of improved arteriole density. In spite of the recent success, limitations with regard to alginate material include poor cell attachment and infiltration, as the hydrophilic nature of alginate hampers protein adsorption and mammalian cell interaction. ${ }^{175}$ Additionally, since alginate is derived from nonmammalian sources, it is likely that they do not provide the desired cardiac extracellular milieu.

\section{Fibrin}

Fibrin, a critical component of blood, is responsible for hemostasis, and is extensively employed in tissue engineering in many forms, such as fibrin hydrogels, fibrin glue, and fibrin microbeads. ${ }^{176}$ It is a fibrillar protein involved in the coagulation cascade, wound healing, ${ }^{177}$ and encouraging angiogenesis. ${ }^{81}$ Fibrin glue is FDA-approved, and hence is frequently used as a surgical adhesive and sealant. Fibrin glue, consisting primarily of two components - enriched fibrinogen and thrombin - was the original material used to study whether an injectable biomaterial can promote cell adhesion, neovascularization, and maintain cardiac function with/without cells. ${ }^{166,178}$ Fibrin injected into rat hearts after creation of infarction by ischemia-reperfusion injury yielded positive results. ${ }^{179}$ Christman et al used $0.5 \%$ bovine serum albumin in saline, fibrin glue alone, SkMs alone, or SkMs in fibrin glue, and injected these materials into the ischemic LV of an acute rat MI model. Echocardiography results showed that fibrin glue injection with/without SkMs preserved LV geometry and cardiac function. ${ }^{166}$ Further similar results with implantation of BM-MNCs with/without fibrin were obtained. ${ }^{180}$ However, the disadvantage of injection of fibrin is that it requires a double-barreled injection system that is presently not compatible with catheter delivery unless the catheter is flushed with saline between injections. This technique is likely not feasible clinically, as multiple flushes of material into the bloodstream would occur. ${ }^{181}$

\section{Chitosan}

Chitosan is derived from a structural component of crustacean shells; it is a polysaccharide with amenable chemistry that allows control of degradation properties. ${ }^{182}$ It is comprised of glucosamine and $N$-acetyl glucosamine units linked by $\beta(1-4)$ glycosidic bonds. The ability of chitosan at physiologic temperature to have temperature-phase transition allows it to gel in situ upon injection into the myocardium with/without cells. The study demonstrated that a thermally responsive chitosan formed by mixing chitosan with $\beta$-glycerol phosphate and hydoxyethyl cellulose, when injected into infarcted rat hearts 1 week after an ischemia-reperfusion injury showed enhanced cell preservation and engraftment upon injection with chitosan, as well as improved function and neovascularization. ${ }^{183}$ Thermal responsiveness favors chitosan to be optimized for injection, with attainable elastic moduli over $5 \mathrm{kPa}$ tested after gelation. ${ }^{184}$ Another study demonstrated a novel material combination of azidobenzoic acid-modified chitosan with acryloyl poly(ethylene glycol)RGDS to make a photo-cross-linkable gel for injection. ${ }^{185}$ This material formed a gel in situ after 2 minutes' ultraviolet irradiation and had a shear modulus up to $370 \mathrm{~Pa}$, besides supporting cell proliferation similar to tissue-culture polystyrene and was also able to release VEGF in vitro for more than 24 days. Although this material is yet to be studied in vivo, it does signify the building interest in material properties through improved material design for the field of CTE. Limitations for employing chitosan include lack of solubility in neutral solutions and unpredictability in cellular attachment for tissue engineering. ${ }^{175}$

\section{Collagen}

Collagen is the most abundant protein in animals and exhibits excellent biodegradability, weak antigenicity, and superior biocompatibility. Collagen has a helical structure with a definite pattern of amino acid sequences that is easily recognized by the body; it is the main protein component of most ECM, and is hence the most frequent material of choice for tissue-engineering applications. ${ }^{186}$ Commercially available collagen products have been used as injectable scaffolds for CTE. ${ }^{81,165}$ Injection of collagen as an acellular treatment into the infarcted myocardium demonstrated improved LV geometry and cardiac functionality without improved vascularization in comparison to saline controls. ${ }^{165}$ Another study 
also demonstrated that collagen matrices could improve the retention of transplanted cardiomyoblasts and favor functional improvement of ischemic rat hearts, which was further confirmed by optical bioluminescence imaging. ${ }^{187,188}$ It was also demonstrated that collagen matrix promoted progenitor cell retention and limited the circulation to nonspecific sites, as evidenced by positron emission tomography imaging, biodistribution, and histology. ${ }^{189}$ Injection of $100 \mu \mathrm{L}$ of collagen at a particular point in the infarct zone led to a higher ejection fraction than saline injection 6 weeks after treatment. However, the injected material did not allow cell penetration or angiogenesis, and thus behaved similarly to the native collagen-rich infarcted region. The improved ejection fraction may have been a consequence of the augmented wall thickness that was noticed after injection. ${ }^{190}$ Contrarily, other studies showed improved myocardial angiogenesis and myofibroblast infiltration into injected collagen. ${ }^{191}$ The rationale behind these contrasting results could be due to the infarct model. No cell penetration or angiogenesis was seen when collagen was injected 1 week after infarction, while there was cell penetration if injected after just 30 minutes of ischemia. These data may further reveal the complexity of salvaging late-stage diseased tissue and necessitates the significance of timing for clinical applications.

\section{Matrigel}

Matrigel is a purified matrix derived from Engelbreth-HolmSwarm mouse sarcoma cells and comprises an intricate mixture of collagen IV, laminin, heparan sulfate proteoglycans, entactin, and growth factors. Matrigel injection was able to form a collagen fiber network that ran parallel to the host myocardium and integrated with native collagen. ${ }^{192}$ In subsequent research, Matrigel-based liquid cell mixture was injected into the infarcted myocardium in a rat heterotopic heart-transplantation model, and the results demonstrated that the injected biomaterial restored the geometry and function of the heart. ${ }^{193}$ A mixture of Matrigel, collagen, and cellculture medium was used to deliver cardiomyocytes, and it showed preserved cardiac geometry and function. ${ }^{41}$ However, there are certain limitations associated with Matrigel, as it is obtained from a mouse sarcoma cell line, is not tissue-specific, and presents the risk of tumor formation, ${ }^{194}$ which will likely limit its therapeutic potential. Besides, Matrigel may not be conducive to neovascularization, as a recent study revealed. ${ }^{191}$ In another study, lack of both cellular penetration and vascular cell infiltration into injected Matrigel was also reported. ${ }^{195}$

\section{Decellularized ECM}

Decellularization necessitates physical, chemical, or enzymatic removal of cellular content from an organ or tissue, leaving only the ECM. Even though it may alter the ECM's chemical and structural components, decellularization is advantageous, as it favors removal of cellular antigens, which could induce an immune response, inflammation, and potential transplant rejection. ${ }^{196}$ Moreover, decellularized materials offer the benefit of being cardiac-specific and potentially autologous injectable therapies. Studies have shown that decellularized porcine ventricular tissue and porcine and human pericardial tissue can be processed to obtain a solubilized liquid with the ability to gel via selfassembly at physiologic temperature upon injection into the myocardium, both in vitro and in vivo. ${ }^{197,198}$ Moreover, gelation of myocardial matrix occurs with the proper kinetics to allow for transendocardial catheter delivery, as examined in a porcine model. ${ }^{181}$ Each tissue has its particular ECM, designed for and secreted by those particular cells, signifying that there are tissue-specific interactions between cells and the ECM. ${ }^{199}$ Thus, decellularized myocardial matrix could mimic the native myocardial ECM's chemical and biological cues, providing the most suitable scaffold. Studies have demonstrated the use of decellularized rat hearts as a whole scaffold for seeding endothelial cells and cardiomyocytes. ${ }^{200}$ Surprisingly, rat endothelial cells formed single layers around vessels within the heart construct, signifying that chemical cues were retained in the decellularized ECM to direct cells. Several groups have studied other decellularizing tissues, such as liver, small intestine, urinary bladder, dermis, blood vessels, and heart valves for several tissue-engineering applications. ${ }^{196,199}$ For instance, in a study by Zhao et al, small-intestine ECM emulsion was injected into the infarcted myocardium, and its efficacy in recruiting cells was evaluated. Histological examination and echocardiography results revealed that injection of ECM emulsion into the infarcted myocardium increased neovascularization and preserved cardiac function, essentially by enhanced recruitment of c-kit cells, myofibroblasts, and macrophages, proving that cardiac remodeling can be modified by supplying ECM after MI. ${ }^{201}$ However, for cardiac applications, materials like small-intestine submucosa and urinary bladder matrix have been examined to form unwanted tissue, such as cartilage in the myocardium, ${ }^{202}$ maybe because they do not provide cardiac-specific cues for cell-matrix interactions in the cardiac environment. 


\section{Comparative studies}

Very few studies have directly compared different types of materials used for CTE. ${ }^{179,191}$ These include collagen-Matrigel, ${ }^{41}$ a fibrin-alginate biocomposite, ${ }^{203}$ and a poly(ethylene glycol) PEGylated fibrin biomatrix. ${ }^{204}$ Even though these combinations provide a more intricate scaffold, they do not completely mimic the cardiac ECM. In these, the precise differences in properties of materials can be directly linked to study outcomes, since all other parameters were kept constant. For instance, in a study, fibrin, Matrigel and collagen were each injected 1 week after an ischemia-reperfusion injury into separate rat groups. Although deficient in cardiac functionality data, this study showed that for all three materials, there was a related increase in capillary density, myofibroblast infiltration, and arteriole density in comparison to saline injection. In a study, comparison was made between alginate and fibrin, and the significance of material residence time was analyzed. ${ }^{179}$ After 2 days of injection, both these materials resulted in comparable decrease in intraventricular diameter, increase in wall thickening and, increased fractional shortening (FS). After 5 weeks, the fibrin-injected hearts did not show improved function, in spite of preserving LV wall thickness, as shown in Figure 7. Alginate, however, improved FS, although at levels less than was shown at 2 days. Infarct size was appreciably reduced in the fibrin group, and there was a trend towards a smaller MI in the alginate group. Another difference was that alginate was still there in considerable amounts even after 5 weeks, while fibrin was totally resorbed after transplantation. ${ }^{179}$ Table 3 gives a list of potential biomaterials employed for cardiac regeneration and their properties.

\section{Self-assembling peptides}

Peptides with particularly placed sequences of amino acid can self-assemble into macroscopic materials that can support cell growth and have been considered as injectable systems for CTE. ${ }^{205,206}$ Peptides with amino acid sequence AcNRARADADARARADADA-CNH2 (RAD16-II) can form a nanofibrous 3-D gel, and have been analyzed as an injectable material to treat MI. Davis et al ${ }^{195}$ also showed that selfassembling peptides (SAPs) are suitable for cell and vessel ingrowth in vivo. Upon injection of $10 \mu \mathrm{L}$ of peptide gel alone at the infarct site, progenitor cells expressing endothelial cell markers and vascular smooth-muscle cells were incorporated

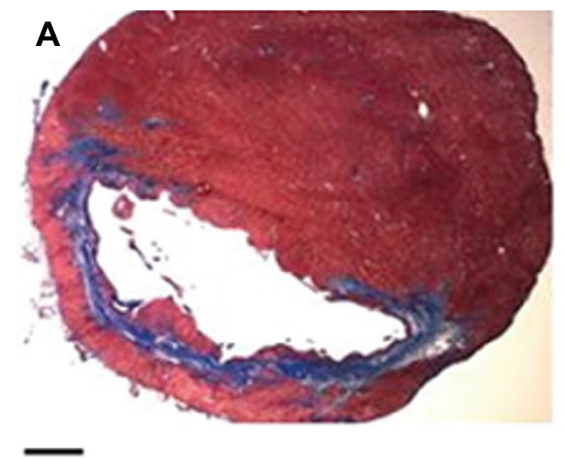

D

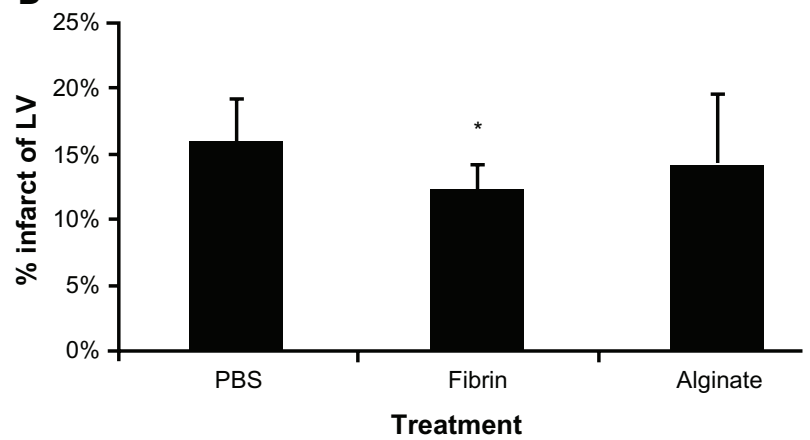

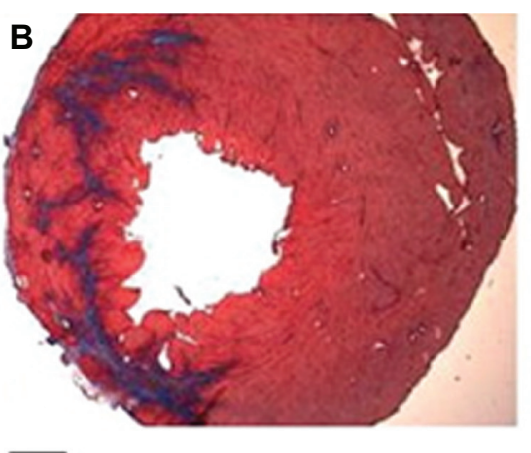

E

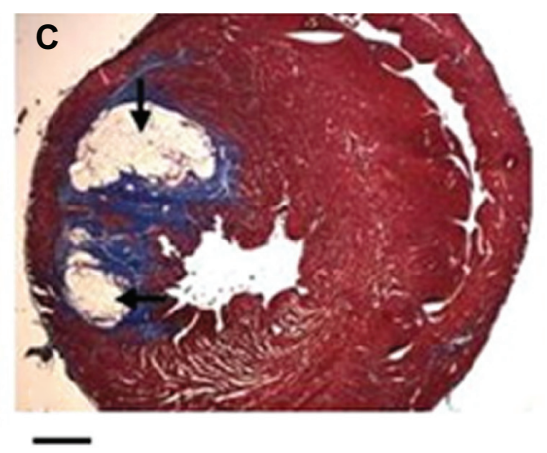

\begin{tabular}{lccl}
\hline $\begin{array}{l}\text { LV wall } \\
\text { thickness, } \mathrm{mm}\end{array}$ & PBS & Fibrin & Alginate \\
\hline Anterior & $1.43 \pm 0.24$ & $1.86 \pm 0.59$ & $3.44 \pm 0.99^{*}$ \\
Lateral & $1.45 \pm 0.31$ & $1.81 \pm 0.23^{*}$ & $2.27 \pm 0.77^{*}$ \\
Posterior & $1.71 \pm 0.40$ & $2.60 \pm 0.71^{*}$ & $2.85 \pm 0.87^{*}$ \\
Septal & $3.10 \pm 0.60$ & $3.42 \pm 0.54$ & $3.01 \pm 0.61$ \\
\hline
\end{tabular}

Figure 7 (A-E) Histologic assessment 5 weeks after injection. Masson's trichrome staining showed the collagen deposition (blue) in the infarcted areas of the phosphatebuffered saline- (PBS; A), fibrin- (B), and alginate- (C) injected groups. Black arrows indicate the existence of alginate. The infarcted percentage of the left ventricle (LV; D) and wall thickness $(\mathbf{E})$ were measured.

Note: Scale bars $=1.0 \mathrm{~mm}$. *represents $P<0.05$.

Reprinted from J Thorac Cardiovasc Surg. Yu J, Christman KL, Chin E, Sievers RE, Saeed M, Lee RJ. Restoration of left ventricular geometry and improvement of left ventricular function in a rodent model of chronic ischemic cardiomyopathy. I37:180-187. Copyright (2009) with permission from Elsevier. ${ }^{179}$ 
Table 3 List of polymer biomaterials and their properties

\begin{tabular}{|c|c|c|c|c|}
\hline Biomaterial & $\begin{array}{l}\text { Elastomer }(\mathrm{E}) / \\
\text { thermoplastic }(\mathrm{T})\end{array}$ & $\begin{array}{l}\text { Young's modulus } \\
\text { (stiffness) }\end{array}$ & $\begin{array}{l}\text { Tensile } \\
\text { strength }\end{array}$ & $\begin{array}{l}\text { Degradation } \\
\text { (months) }\end{array}$ \\
\hline PGA & $\mathrm{T}$ & $7-10 \mathrm{GPa}$ & $70 \mathrm{MPa}$ & $2-12$ \\
\hline PLLA & $\mathrm{T}$ & $\mathrm{I}-4 \mathrm{GPa}$ & $30-80 \mathrm{MPa}$ & $2-12$ \\
\hline PHB & $E$ & $2-3 \mathrm{GPa}$ & $36 \mathrm{MPa}$ & Degradable \\
\hline PPD or PDS & $\mathrm{E}$ & $0.6 \mathrm{GPa}$ & $12 \mathrm{MPa}$ & 6 \\
\hline TMC & $\mathrm{E}$ & $6 \mathrm{MPa}$ & $12 \mathrm{MPa}$ & Degradable \\
\hline POC & $\mathrm{T}$ & $\mathrm{I}-16 \mathrm{MPa}$ & $6.7 \mathrm{MPa}$ & Degradable \\
\hline PGS & $\mathrm{E}$ & $0.04-1.2 \mathrm{MPa}$ & $0.2-0.5 \mathrm{MPa}$ & Degradable \\
\hline Collagen fiber (tendon bone) & $\mathrm{E}$ & $2-46 \mathrm{MPa}$ & $\mathrm{I}-7 \mathrm{MPa}$ & Degradable \\
\hline Collagen gel (calf skin) & $\mathrm{E}$ & $0.002-0.022 \mathrm{MPa}$ & $\mathrm{I}-9 \mathrm{kPa}$ & Degradable \\
\hline Rat myocardium & $\mathrm{E}$ & $0.00 \mathrm{I}-0.14 \mathrm{MPa}$ & $30-70 \mathrm{kPa}$ & NA \\
\hline Human myocardium & $\mathrm{E}$ & $0.02-0.5 \mathrm{MPa}$ & $3-15 \mathrm{kPa}$ & NA \\
\hline
\end{tabular}

Abbreviations: PGA, Poly glycolic acid; PLLA, Poly I-lactic acid; PHB, Polyhydroxybutyrate; PPD, p-Phenylenediamine; TMC, trimethylenecarbonate; POC, poly(octanediolco-citrate); PGS, Poly(glycerol sebacate).

into the nanofibers. Neonatal cardiomyocytes injected with the nanofibers were also found to improve recruitment of endogenous cells. Injection of $80 \mu \mathrm{L}$ of the same material into a sham animal model in a parallel work resulted in a temporary decline in FS and LV end-systolic diameters before going back to normal levels after 2 months. ${ }^{207}$ Thus, while this material may be beneficial on the cellular aspect, the addition of noncontractile material to the myocardium may have a transient negative consequence on systolic function of the heart. In another study, RAD16-II nanofiber injection into a rat heart instantly after coronary ligation was not able to progress cardiac geometry, function, or histology in comparison to control MI groups. ${ }^{208,209}$ This lack of progress has not been studied, but may be due to much less material being injected or the material not being mechanically robust. Variable results have been obtained with regard to injection of SAPs in MI models, wherein success has only been accomplished with the inclusion of tethered growth factors, with varying results depending on the growth factor and the cell type injected in MI rats.

\section{Synthetic hydrogels}

Hydrogels have high water content and diffusivity, and hence are widely employed for tissue-engineering applications. Studies have shown that injection of PEG hydrogel into the MI heart initially resulted in augmented wall thickness and attenuated dilation. ${ }^{210}$ However, these effects persisted for only the first 4 weeks; by 3 months, the hydrogel-injection group had retrograded to cardiac function and geometry similar to that of the control saline group. The authors suggested that PEG may be an adequate mechanical support originally, but as the myocardium continues to dilate, the wall stresses ultimately become more than the PEG hydrogel can sustain, and remodeling of $L V$ continues uncurbed. Thermoresponsive hydrogels like $N$-isopropyl acrylamide were also studied for CTE. In one study, a degradable, thermally responsive copolymer of $\mathrm{N}$-isopropylacrylamide, acrylic acid, and hydroxyl(ethyl) methacrylate-poly(trimethylene carbonate) was developed. ${ }^{211}$ The sol-gel transition of this polymer occurred at about $33^{\circ} \mathrm{C}$. The authors demonstrated that injection of this material into a chronic rat infarction model prohibited the progression of cardiac dilation and remodeling. Besides cellular penetration into the material, histological analysis of the LV wall 8 weeks after injection revealed formation of a layer of smooth muscle next to the remaining material, which showed protein expression related to a contractile phenotype, suggesting potential use of this material for CTE. Studies have reported the cooperative roles of stromal cell-derived factor 1a (SDF-1a) and hyaluronic acid (HA) in order to enhance endogenous BMCs homing to the heart, subsequent to MI. In particular, recombinant SDF-1a was encapsulated in degradable HA hydrogels that form in situ on the heart, in order to localize SDF-1a and HA homing cues to favor cardiac remodeling for improved engraftment of circulating BMCs in the myocardium. Their motivation for choosing HA as a biomaterial for MI was because (1) HA is the major ligand for CD44, which is responsible for cell motility processes that govern BMC homing, and (2) HA is a negatively charged glycosaminoglycan that can regulate chemokines in tissues. ${ }^{212}$ In another recent study, the efficiency of silk fibroin and $\mathrm{HA}(\mathrm{SH})$ in combination with BMSC was demonstrated for MI heart repairs. The authors reported that $\mathrm{BMSC} / \mathrm{SH}$ significantly enhanced the survival of delivered BMCS, prevented cell apoptosis, restored contractile proteins, and stimulated secretion of growth factors for cardiac repairs in MI zones of the hearts. ${ }^{213}$ In a recent study, a biodegradable, injectable hydrogel composite of oligo(poly[ethylene glycol] fumarate) 
(OPF) was studied as a carrier of mouse embryonic stem cells (mESCs) for treatment of MI. Echocardiography and histological analysis were performed, and it was found that in the presence of ascorbic acid, the mESCs differentiated into cardiomyocytes and other cell types in all three lineages in the OPF hydrogel. The study concluded that besides OPF with mESCs, OPF hydrogel alone also showed significantly reduced collagen deposition and infarct size and improved LV function, highlighting the potential of OPF hydrogels for stem cell retention and transplantation for regeneration of MI. ${ }^{214}$ OPF has the advantages of being inert, so does not induce any inflammatory response, it is easy and cost-effective to manufacture, and it is synthetic, annulling the possibility of pathogen transfer. A major challenge associated with the use of synthetic hydrogels for CTE includes controlling the development of hydrogel structure in situ after injection. Although weak hydrogels may be forced through a needle, the material property may be insufficient for such a mechanically robust environment as the cardiac muscle, and hence a more mechanically suitable biomaterial is desired.

\section{Injection of growth factors}

In situ regeneration in the infarcted myocardium may be stimulated by delivery of cytokines that induce homing of stem cells in the region of infarction, which in turn may differentiate into endothelial cells and cardiomyocytes, eventually leading to regeneration of myocardium. These cytokines include granulocyte colony-stimulating factor (G-CSF), SDF-1, IGF-1, leukemia inhibitory factor, and erythropoietin. ${ }^{49}$ It was demonstrated that intramyocardial injection of a hepatocyte growth factor and IGF-1 stimulates resident cardiac progenitor cells to form myocytes and coronary vessels within the region of infarction and results in progress in the contractile performance. ${ }^{101}$ Table 4 provides the list of growth factors and their functions. Studies have shown that incorporation of IGF-1 with SAPs favors cardiomyocyte survival, improves cardiac function, ${ }^{215}$ and improves proliferation of cardiac progenitor cells. ${ }^{216}$ Another study demonstrated that G-CSF mobilizes stem cells, and these undergo cardiogenic differentiation. ${ }^{217} \mathrm{G}-\mathrm{CSF}$ was also shown to prevent LV remodeling, improve cardiac function, increase angiogenesis, and decrease apoptosis. ${ }^{218}$ In another study, G-CSF and stem cell factor mobilized hematopoietic progenitor cells from bone marrow into circulation and resulted in improvement in LV function. However, the factors did not prevent remodeling or replace the scar tissue with new muscle cells. This suggested that the combination of G-CSF and stem cell factor improves LV function by enhancing the functional reserve of the myocardium, and not by replacing the muscle. ${ }^{219}$

Angiogenic factors like VEGF are also necessary for improving the MI microenvironment. For instance, targeted delivery of VEGF using encapsulating immunoliposomes into the MI zone has been shown to significantly enhance morphology and function of infarcted region. ${ }^{220}$ Iwakura et $\mathrm{a}^{221}$ delivered basic FGF via injectable gelatin microspheres and demonstrated improved angiogenesis and cardiac function. Delivery of a plasmid encoding the angiogenic growth factor pleiotrophin in fibrin glue also increased neovascularization in infarcted myocardium. ${ }^{222}$ SAPs as a delivery vehicle for platelet-derived growth factor BB also showed sustained delivery of growth factor for 14 days in the infarct, which decreased apoptosis, preserved cardiac function, and reduced infarct size compared to either the peptides or the growth factor alone..$^{208}$ Poly(lactic-co-glycolic acid) microspheres incorporated within porous alginate scaffold were capable of controlling the release of angiogenic factors, such as basic FGF. In vitro, basic FGF was control-released, and it was biologically active as evaluated by its capability to induce cardiac fibroblast proliferation. ${ }^{223}$ These diverse results suggest the importance of injecting growth factors to create an appropriate milieu for the cell type/ biomaterial being injected into the ischemic myocardium.

Table 4 Source of growth factors and functions

\begin{tabular}{lll}
\hline Growth factors & Source & Function \\
\hline VEGF & Endothelial cells & Angiogenesis \\
PDGF & Platelets, endothelial cells, placenta & Promotes proliferation of connective tissue and smooth muscle cells \\
EGF & Submaxillary gland, Brunner's glands & Promotes proliferation of mesenchymal, glial, and epithelial cells \\
TGF- $\alpha$ & Transformed cells & Wound healing \\
TGF- $\beta$ & Activated $\mathrm{T}_{\mathrm{h}}$ I cells (T-helper) and natural killer (NK) cells & Anti-inflammatory, wound-healing \\
EPO & Kidney & Promotes proliferation and differentiation of erythrocytes \\
IGF-I & Liver & Proliferation of various cells \\
FGF & Wide range of cells & Promotes proliferation of many cells \\
\hline
\end{tabular}

Abbreviations: VEGF, vascular endothelial growth factor; PDGF, platelet-derived growth factor; EGF, epidermal growth factor; TGF, transforming growth factor; EPO, erythropoietin; IGF, insulin-like growth factor; FGF, fibroblast growth factor. 


\section{Limitations of an injectable system}

The significant limitation in the injection of biomaterials with or without cells is that it depends mainly on the cells to improve cardiac function, without considering biological and mechanical properties of the biomaterials employed. Most of the biomaterials employed have unmatched mechanical properties to the infarcted myocardium. The stiffness of a range of possible injectable materials is in the range of $10 \mathrm{~Pa}$ to $20 \mathrm{kPa}$, such as fibrin (50 Pa), ${ }^{224}$ Matrigel $(30-120 \mathrm{~Pa}),{ }^{225}$ type I collagen gels (20-80 Pa for $1-3 \mathrm{mg} / \mathrm{mL}),{ }^{226}$ bioactive hydrogels based on $N$-isopropylacrylamide $(100-400 \mathrm{~Pa}),{ }^{227,228}$ alginate (100 Pa to $6 \mathrm{kPa}),{ }^{229}$ and PEG $(1-3 \mathrm{kPa}){ }^{230}$ These biomaterials are significantly softer than the human cardiac muscle at the end of diastole, the stiffness of which is $50 \mathrm{kPa}$ in normal hearts or $200-300 \mathrm{kPa}$ in congestive heart-failure hearts. ${ }^{231}$ Thus, it is not possible that they could provide satisfactory mechanical support to the infarcted heart. Also, the biomaterials ought to be biodegradable ECMs, so that they may be degraded over a period of time when implanted in vivo upon the functional improvement and regeneration of the infarcted myocardium to its native ECM. Additionally, few biomaterials have slow gelation rates, which may raise the likelihood of blocking the flow of blood, causing tissue necrosis in vivo. ${ }^{232}$ Hence, it is necessary to engineer a suitable biomaterial system with mechanical properties similar to that of the native myocardium.

\section{Future perspectives}

Given the intricate anisotropic mechanical behavior of myocardium, it is not easy to produce a polymer that responds to mechanical stresses similar to the heart. Moreover, mammalian heart is not purely composed of cardiomyocytes alone, but is comprised of cardiomyocytes, smooth-muscle cells, fibroblasts, macrophages, endothelial cells, and other cells of leukocytotic origin. Nonmyocytes play a crucial role in heart and cardiomyocyte development, function, and hypertrophy. Therefore, concepts have to be developed taking into consideration the various cell types in the heart that would be required for successful tissue-engineered constructs. It has been proposed that cardiac grafts should survive and be vascularized after implantation/injection. ${ }^{232}$ Besides their paracrine mechanism, adult stem cell grafts will most likely not be able to support vascularization and long-term cell survival after injection. Hence, vital aspects such as thickness of the graft and the need for prevascularization prior to implantation should be considered. The heart, being an intricate organ, has more than three dimensions, featuring rhythm and contractility. Additionally, it is nonsymmetric and nonisotropic, with variable anatomy and microstructure. To fulfill the functional demands comparably well to natural heart muscle, more sophisticated technology is necessary. With the advancement of tissue engineering and nanotechnology, more robust products can be developed. Further, the release of cytokines and bioactive proteins in a controlled manner through nanostructured materials with appropriate biological and mechanical properties would be the ultimate mode for improving heart function. Development of materials involving injectable polymeric scaffolds suitable for catheter delivery allows for establishment of cellular milieu more desirable for CTE. Although each CTE technique brings about myocardial functional enhancement, the mechanisms of repair pathways are still unclear. It would be worth considering whether it is the functional activity of cells injected or structural changes brought about by biomaterial injection that is responsible for repair of the infarcted heart. Long term in vivo studies are required to understand these crossroads of tissue engineering, biomaterials, myocardial repair, stem cells, and growth factors. Additionally, the optimum design parameters, injectability potential, degradation rate, elastic modulus, and several other properties are still to be elucidated and therefore offer a fertile area for a hypothesis-driven injectable system.

\section{Conclusion}

The design of innovative therapeutics that allow nonsurgical delivery into the patient and induce the least morbidity will play a pivotal role clinically in treating MI. Surgical techniques aiming at implantation of bioengineered cardiac patches via laparoscopic routes need preclinical investigation. Achievement of all prevailing models succeeds or fails with their clinical pertinence. If a new technique to treat cardiac failure is to be made available to patients, it is desirable that it cannot be more invasive than the existing major cardiac procedures. This may render cardiac tissue engineering, with any cell source, a possible clinical choice, which may compete with the existing ones. It is widely known that injecting cells is not the only option for myocardial repair, and that tissue-engineered biomaterial scaffolds should also be used to provide structural support to the heart wall whilst delivering the necessary cytokines, proteome, and genes that will stimulate efficiently the heart's inherent regenerative mechanism. In summary, these studies confirmed the feasibility of using a minimally invasive injectable CTE approach for treatment of myocardial infarction. Nevertheless, the type of biomaterial, timing, dose, and injection technique is still uncertain to accomplish success in cardiac tissue engineering. 


\section{Acknowledgments}

This study was supported by NRF-Technion (R-398-001065-592), Ministry of Education (R-265-000-318-112), and NUSNNI, National University of Singapore, Singapore.

\section{Disclosure}

The authors report no conflicts of interest in this work.

\section{References}

1. Rosamond W, Flegal K, Furie K, et al. Heart disease and stroke statistics - 2008 update: a report from the American Heart Association Statistics Committee and Stroke Statistics Subcommittee. Circulation. 2008;117:e25-e146.

2. Baig MK, Mahon N, McKenna WJ, et al. The pathophysiology of advanced heart failure. Heart Lung. 1999;28:87-101.

3. Sarig U, Machluf M. Engineering cell platforms for myocardial regeneration. Expert Opin Biol Ther. 2011;11:1055-1077.

4. Tous E, Purcell BP, Ifkovits JL, Burdick JA. Injectable acellular hydrogels for cardiac repair. J Cardiovasc Transl Res. 2011;4:528-542.

5. Rane AA, Christman KL. Biomaterials for the treatment of myocardial infarction a 5-year update. J Am Coll Cardiol. 2011;58:2615-2629.

6. Nunes SS, Song H, Chiang CK, Radisic M. Stem cell-based cardiac tissue engineering. J Cardiovasc Transl Res. 2011;4:592-602.

7. Beitnes JO, Lunde K, Brinchmann JE, Aakhus S. Stem cells for cardiac repair in acute myocardial infarction. Expert Rev Cardiovasc Ther 2011;9:1015-1025.

8. Chiu LL, Iyer RK, Reis LA, Nunes SS, Radisic M. Cardiac tissue engineering:current state and perspectives. Front Biosci. 2012;17: 1533-1550.

9. LeGrice IJ, Smaill BH, Chai LZ, Edgar SG, Gavin JB, Hunter PJI. Laminar structure of the heart: ventricular myocyte arrangement and connective tissue architecture in the dog. Am J Physiol. 1995;269: H571-H582.

10. Smaill BH, Hunter PJ. Theory of Heart. New York, NY: Springer-Verlag; 1991.

11. Goldsmith EC, Hoffman A, Morales MO, et al. Organization of fibroblasts in the heart. Dev Dyn. 2004;230:787-794.

12. Eghbali M, Blumenfeld OO, Seifter S, et al. Localization of types I, III, IV collagen mRNAs in rat heart cells by in situ hybridization. $J \mathrm{Mol}$ Cell Cardiol. 1989;21:103-113.

13. Bosman FT, Stamenkovic I. Functional structure and composition of the extracellular matrix. J Pathol. 2003;200:423-428.

14. Bing OH, Ngo HQ, Humphries DE, et al. Localization of alpha1(I) collagen mRNA in myocardium from the spontaneously hypertensive rat during the transition from compensated hypertrophy to failure. J Mol Cell Cardiol. 1997;29:2335-2344.

15. Robinson TF, Geraci MA, Sonnenblick EH, Factor SM. Coiled perimysial fibers of papillary muscle in rat heart: morphology, distribution, and changes in configuration. Circ Res. 1988;63:577-592.

16. Borg TK, Johnson LD, Lill PH. Specific attachment of collagen to cardiac myocytes: in vivo and in vitro. Dev Biol. 1983;97:417-423.

17. Chang AC, Towbin JA. Heart Failure in Children and Young Adults: From Molecular Mechanisms to Medical and Surgical Strategies. Philadelphia, PA: Saunders Elsevier; 2006.

18. Zimmermann WH, Didie M, Doker S, et al. Heart muscle engineering: an update on cardiac muscle replacement therapy. Cardiovasc Res. 2006;71:419-429.

19. Zimmermann WH, Melnychenko I, Wasmeier G, et al. Engineered heart tissue grafts improve systolic and diastolic function in infarcted rat hearts. Nat Med. 2006;12:452-458.

20. Torrent-Guasp F, Ballester M, Buckberg GD, et al. Spatial orientation of the ventricular muscle band: physiologic contribution and surgical implications. J Thorac Cardiovasc Surg. 2001;122:389-392.
21. McMurray JJ, Pfeffer MA. Heart failure. Lancet. 2005;365: 1877-1889.

22. Packer M. The impossible task of developing a new treatment for heart failure. J Card Failure. 2002;8:193-196.

23. Taylor DO, Stehlik J, Edwards LB, et al. Registry of the International Society for Heart and Lung Transplantation: Twenty-Sixth Official Adult Heart Transplant Report - 2009. J Heart Lung Transplant. 2009;28: 1007-1022.

24. Smith RR, Barile L, Messina E, Marban E. Stem cells in the heart: what's the buzz all about? Part 2: arrhythmic risks and clinical studies. Heart Rhythm. 2008;5:880-887.

25. Mason C, Dunnill P. A brief definition of regenerative medicine. Regen Med. 2008:3:1-5.

26. Kelley ST, Malekan R, Gorman JH, et al. Restraining infarct expansion preserves left ventricular geometry and function after acute anteroapical infarction. Circulation. 1999;99:135-142.

27. Chaudhry PA, Mishima T, Sharov VG, et al. Passive epicardial containment prevents ventricular remodeling in heart failure. Ann Thorac Surg. 2000;70:1275-1280.

28. Walsh RG. Design and features of the Acorn CorCap Cardiac Support Device: the concept of passive mechanical diastolic support. Heart Fail Rev. 2005;10:101-107.

29. Christman KL, Lee RJ. Biomaterials for the treatment of myocardial infarction. J Am Coll Cardiol. 2006;48:907-913.

30. Klodell CT Jr, Aranda JM Jr, McGiffin DC, et al. Worldwide surgical experience with the Paracor HeartNet cardiac restraint device. JThorac Cardiovasc Surg. 2008;135:188-195.

31. Li RK, Jia ZQ, Weisel RD, Mickle DA, Choi A, Yau TM. Survival and function of bioengineered cardiac grafts. Circulation. 1999;100: II63-II169.

32. Leor J, Aboulafia-Etzion S, Dar A, et al. Bioengineered cardiac grafts: a new approach to repair the infarcted myocardium? Circulation. 2000;102:III56-III61.

33. Kofidis T, de Bruin JL, Hoyt G, et al. Myocardial restoration with embryonic stem cell bioartificial tissue transplantation. J Heart Lung Transplant. 2005;24:737-744.

34. Zimmermann WH, Didie M, Wasmeier GH, et al. Cardiac grafting of engineered heart tissue in syngenic rats. Circulation. 2002;106: I151-I157.

35. Tulloch NL, Muskheli V, Razumova MV, et al. Growth of engineered human myocardium with mechanical loading and vascular coculture. Circ Res. 2011;109:47-59.

36. Fujimoto KL, Tobita K, Merryman WD, et al. An elastic, biodegradable cardiac patch induces contractile smooth muscle and improves cardiac remodeling and function in subacute myocardial infarction. J Am Coll Cardiol. 2007;49:2292-2300.

37. Yamada N, Okano T, Sakai H, Karikusa F, Sawasaki Y, Sakurai Y. Thermo-responsive polymeric surfaces; control of attachment and detachment of culture cells. Macromol Chem Rapid Commun. 1990;11: 571-576.

38. Okano T, Yamada N, Sakai H, Sakurai Y. A novel recovery system for cultured cells using plasma-treated polystyrene dishes grafted with poly(N-isopropylacrylamide). J Biomed Mater Res. 1993;27: 1243-1251.

39. Guo XM, Zhao YS, Chang HX, et al. Creation of engineered cardiac tissue in vitro from mouse embryonic stem cells. Circulation. 2006;113: 2229-2237.

40. Shimizu T, Yamato M, Isoi Y, et al. Fabrication of pulsatile cardiac tissue grafts using a novel 3-dimensional cell sheet manipulation technique and temperature-responsive cell culture surfaces. Circ Res. 2002;90:e40-e48.

41. Zhang $\mathrm{P}$, Zhang H, Wang H, Wei Y, Hu S. Artificial matrix helps neonatal cardiomyocytes restore injured myocardium in rats. Artif Organs. 2006;30:86-93.

42. Sekiya S, Shimizu T, Yamato M, Kikuchi A, Okano T. Bioengineered cardiac cell sheet grafts have intrinsic angiogenic potential. Biochem Biophys Res Commun. 2006;341:573-582. 
43. Radisic M, Deen W, Langer R, Vunjak-Novakovic G. Cardiac muscle tissue engineering: toward an in vitro model for electrophysiological studies. Am J Physiol Heart Circ Physiol. 2005;288:1278-1289.

44. Ravichandran R, Venugopal JR, Sundarrajan S, Mukherjee S, Ramakrishna S. Poly(glycerol sebacate)/gelatin core/shell fibrous structure for regeneration of myocardial infarction. Tissue Eng Part A. 2011;17:1363-1373.

45. Wang Y, Ameer GA, Sheppard BJ, Langer R. A tough biodegradable elastomer. Nat Biotechnol. 2002;20:602-606.

46. Chen QZ, Bismarck A, Hansen U, et al. Characterisation of a soft elastomer poly(glycerol sebacate) designed to match the mechanical properties of myocardial tissue. Biomaterials. 2008;29(1):47-57.

47. Ravichandran R, Venugopal JR, Sundarrajan S, Mukherjee S, Sridhar R, Ramakrishna S. Expression of cardiac proteins in neonatal cardiomyocytes on PGS/fibrinogen core/shell substrate for cardiac tissue engineering. Int J Cardiol. Epub May 5, 2012.

48. Mukherjee S, Venugopal JR, Ravichandran R, Ramakrishna S, Raghunath M. Evaluation of the biocompatibility of PLACL/collagen nanostructured matrices with cardiomyocytes as a model for the regeneration of infarcted myocardium. Adv Funct Mater. 2011;21:2291-2300.

49. Lutolf MP, Hubbell JA. Synthetic biomaterials as instructive extracellular microenvironments for morphogenesis in tissue engineering. Nat Biotechnol. 2005;23:47-55.

50. Ravichandran R, Liao S, Ng CCH, Chan CK, Raghunath M, Ramakrishna S. Effects of nanotopography on stem cell phenotypes. World J Stem Cells. 2009;1:55-66.

51. Leor J, Amsalem Y, Cohen S. Cells, scaffolds, and molecules for myocardial tissue engineering. Pharmacol Ther. 2005;105:151-163.

52. Ravichandran R, Venugopal JR, Sundarrajan S, Mukherjee S, Sridhar R, Ramakrishna S. Minimally invasive injectable short nanofibers of poly(glycerol sebacate) for cardiac tissue engineering. Nanotechnology. 2012;23:385102.

53. Murry CE, Field LJ, Menasché P. Cell-based cardiac repair: reflections at the 10-year point. Circulation. 2005;112:3174-3183.

54. Murry CE, Wiseman RW, Schwartz SM, Hauschka SD. Skeletal myoblast transplantation for repair of myocardial necrosis. J Clin Invest. 1996;98:2512-2523.

55. Murry CE, Soonpaa MH, Reinecke H, et al. Haematopoietic stem cells do not transdifferentiate into cardiac myocytes in myocardial infarcts. Nature. 2004;428:664-668.

56. Mangi AA, Noiseux N, Kong D, et al. Mesenchymal stem cells modified with Akt prevent remodeling and restore performance of infarcted hearts. Nat Med. 2003;9:1195-1201.

57. Beltrami AP, Barlucchi L, Torella D, et al. Adult cardiac stem cells are multipotent and support myocardial regeneration. Cell. 2003;114: $763-776$.

58. Doss MX, Koehler CI, Gissel C, Hescheler J, Sachinidis A. Embryonic stem cells: a promising tool for cell replacement therapy. J Cell Mol Med. 2004;8:465-473.

59. Nelson TJ, Martinez-Fernandez A, Yamada S, Perez-Terzic C, Ikeda Y, Terzic A. Repair of acute myocardial infarction by human stemness factors induced pluripotent stem cells. Circulation. 2009;120:408-416.

60. Wu KH, Liu YL, Zhou B, Han ZC. Cellular therapy and myocardial tissue engineering: the role of adult stem and progenitor cells. Eur $J$ Cardiothorac Surg. 2006;30:770-781.

61. Fukada J, Kurimoto Y, Ruiz P, et al. Long-term survival of rat cardiac allografts by intrathymic plus portal venous injections of donor bone marrow cells and short-term tacrolimus immunosuppression. Transpl Int. 2001;14:311-319.

62. Hamano K, Nishida M, Hirata K, et al. Local implantation of autologous bone marrow cells for therapeutic angiogenesis in patients with ischemic heart disease: clinical trial and preliminary results. Jpn Circ J. 2001;65:845-847.

63. Gao LR, Tang CS, Zhu ZM, et al. The autologous bone marrow mononuclear cell transplantation by intracoronary route treat patients with severe heart failure after myocardial infarction. Zhonghua Xin Xue Guan Bing Za Zhi. 2006;34:582-586. Chinese.
64. Strauer BE, Brehm M, Zeus T, et al. Repair of infarcted myocardium by autologous intracoronary mononuclear bone marrow cell transplantation in humans. Circulation. 2002;106:1913-1918.

65. Assmus B, Schächinger V, Teupe C, et al. Transplantation of progenitor cells and regeneration enhancement in acute myocardial infarction (TOPCARE-AMI). Circulation. 2002;106:3009-3017.

66. Vulliet PR, Greeley M, Halloran SM, MacDonald KA, Kittleson MD. Intra-coronary arterial injection of mesenchymal stromal cells and microinfarction in dogs. Lancet. 2004;363:783-784.

67. Dai W, Hale SL, Kloner RA. Stem cell transplantation for the treatment of myocardial infarction. Transpl Immunol. 2005;15:91-97.

68. Reinecke H, Murry CE. Taking the death toll after cardiomyocyte grafting: a reminder of the importance of quantitative biology. $J \mathrm{Mol}$ Cell Cardiol. 2002;34:251-253.

69. Wang H, Zhou J, Liu Z, Wang C. Injectable cardiac tissue engineering for the treatment of myocardial infarction. J Cell Mol Med. 2010;14: 1044-1055.

70. Teng CJ, Luo J, Chiu RC, Shum-Tim D. Massive mechanical loss of microspheres with direct intramyocardial injection in the beating heart: implications for cellular cardiomyoplasty. J Thorac Cardiovasc Surg. 2006;132:628-632.

71. Wakitani S, Saito T, Caplan AI. Myogenic cells derived from rat bone marrow mesenchymal stem cells exposed to 5-azacytidine. Muscle Nerve. 1995;18:1417-1426.

72. Makino S, Fukuda K, Miyoshi S, et al. Cardiomyocytes can be generated from marrow stromal cells in vitro. J Clin Invest. 1999;103:697-705.

73. Kehat I, Kenyagin-Karsenti D, Snir M, et al. Human embryonic stem cells can differentiate into myocytes with structural and functional properties of cardiomyocytes. J Clin Invest. 2001;108:407-414.

74. Min J, Yang Y, Converso KL, et al. Transplantation of embryonic stem cells improves cardiac function in postinfarcted rats. J Appl Physiol. 2002;92:288-296.

75. Kocher A, Schuster M, Szabolcs M, et al. Neovascularization of ischemic myocardium by human bone-marrow-derived angioblasts prevents cardiomyocyte apoptosis, reduces remodeling and improves cardiac function. Nat Med. 2001;7:430-436.

76. Britten M, Abolmaali N, Assmus B, et al. Infarct remodeling after intracoronary progenitor cell treatment in patients with acute myocardial infarction (TOPCARE-AMI): mechanistic insights from serial contrast-enhanced magnetic resonance imaging. Circulation. 2003;108:2212-2218.

77. Urbich C, Aicher A, Heeschen C, et al. Soluble factors released by endothelial progenitor cells promote migration of endothelial cells and cardiac resident progenitor cells. J Mol Cell Cardiol. 2005;39: 733-742.

78. Takahashi M, Li T, Suzuki R, et al. Cytokines produced by bone marrow cells can contribute to functional improvement of the infarcted heart by protecting cardiomyocytes from ischemic injury. Am J Physiol Heart Circ Physiol. 2006;291:H886-H893.

79. Herrmann JL, Wang Y, Abarbanell AM, Weil BR, Tan J, Meldrum DR. Preconditioning mesenchymal stem cells with transforming growth factor- $\alpha$ improves mesenchymal stem cell-mediated cardioprotection. Shock. 2006;33:24-30.

80. Kim H, Haider H, Jiang S, Ashraf M. Ischemic preconditioning augments survival of stem cells via mir-210 expression by targeting caspase8-associated protein 2. J Biol Chem. 2009;284:33161-33168.

81. Thompson CA, Nasseri BA, Makower J, et al. Percutaneous transvenous cellular cardiomyoplasty. A novel nonsurgical approach for myocardial cell transplantation. J Am Coll Cardiol. 2003;41:1964-1971.

82. Orlic D, Kajstura J, Chimenti S, et al. Bone marrow cells regenerate infarcted myocardium. Nature. 2001;410:701-705.

83. Caspi O, Gepstein L. Stem cells for myocardial repair. Eur Heart J. 2006;8:E43-E54.

84. Solheim S, Seljeflot I, Lunde K, et al. Inflammatory responses after intracoronary injection of autologous mononuclear bone marrow cells in patients with acute myocardial infarction. Am Heart J. 2008;155: e1-e9. 
85. Schachinger V, Erbs S, Elsasser A, et al. Intracoronary bone marrowderived progenitor cells in acute myocardial infarction. $N$ Engl J Med. 2006;355:1210-1221.

86. Lunde K, Solheim S, Aakhus S, et al. Intracoronary injection of mononuclear bone marrow cells in acute myocardial infarction. N Engl J Med. 2006;355:1199-1209.

87. Chen SL, Fang WW, Ye F, et al. Effect on left ventricular function of intracoronary transplantation of autologous bone marrow mesenchymal stem cell in patients with acute myocardial infarction. Am J Cardiol. 2004;94:92-95.

88. Nagaya N, Fujii T, Iwase T, et al. Intravenous administration of mesenchymal stem cells improves cardiac function in rats with acute myocardial infarction through angiogenesis and myogenesis. Am J Physiol Heart Circ Physiol. 2004;287:H2670-H2676.

89. Kinnaird T, Stabile E, Burnett MS, et al. Marrow-derived stromal cells express genes encoding a broad spectrum of arteriogenic cytokines and promote in vitro and in vivo arteriogenesis through paracrine mechanisms. Circ Res. 2004;94:678-685.

90. Caplan AI. Adult mesenchymal stem cells for tissue engineering versus regenerative medicine. J Cell Physiol. 2007;213:341-347.

91. Tang YL, Zhao Q, Qin X, et al. Paracrine action enhances the effects of autologous mesenchymal stem cell transplantation on vascular regeneration in rat model of myocardial infarction. Ann Thorac Surg. 2005;80:229-236.

92. Dai W, Hale SL, Martin BJ, et al. Allogeneic mesenchymal stem cell transplantation in postinfarcted rat myocardium: short- and long-term effects. Circulation. 2005;112:214-223.

93. Balsam LB, Wagers AJ, Christensen JL, et al. Haematopoietic stem cells adopt mature haematopoietic fates in ischaemic myocardium. Nature. 2004;428:668-673.

94. Planat-Benard V, Menard C, Andre M, et al. Spontaneous cardiomyocyte differentiation from adipose tissue stroma cells. Circ Res. 2004;94:223-229.

95. Planat-Benard V, Silvestre JS, Cousin B, et al. Plasticity of human adipose lineage cells toward endothelial cells: physiological and therapeutic perspectives. Circulation. 2004;109:656-663.

96. Zuk PA, Zhu M, Mizuno H, et al. Multilineage cells from human adipose tissue: implications for cell-based therapies. Tissue Eng. 2001; 7:211-228.

97. Fraser JK, Wulur I, Alfonso Z, Hedrick MH. Fat tissue: an underappreciated source of stem cells for biotechnology. Trends Biotechnol. 2006;24:150-154.

98. Miranville A, Heeschen C, Sengenes C, Curat CA, Busse R, Bouloumie A. Improvement of postnatal neovascularization by human adipose tissue derived stem cells. Circulation. 2004;110: 349-355.

99. Choi YS, Matsuda K, Dusting GJ, Morrison WA, Dilley RJ. Engineering cardiac tissue in vivo from human adipose-derived stem cells. Biomaterials. 2010;31:2236-2242.

100. Schenke-Layland K, Strem BM, Jordan MC, et al. Adipose tissue-derived cells improve cardiac function following myocardial infarction. J Surg Res. 2009;153:217-223.

101. Linke A, Muller P, Nurzynska D, et al. Stem cells in the dog heart are self-renewing, clonogenic, and multipotent and regenerate infarcted myocardium, improving cardiac function. Proc Natl Acad Sci U S A. 2005;102:8966-8971.

102. Li Z, Lee A, Huang M, et al. Imaging survival and function of transplanted cardiac resident stem cells. J Am Coll Cardiol. 2009;53: 1229-1240.

103. Bolli R, Chugh AR, D'Amario D, et al. Cardiac stem cells in patients with ischaemic cardiomyopathy (SCIPIO): initial results of a randomised phase 1 trial. Lancet. 2011;378:1847-1857.

104. Joggerst SJ, Hatzopoulos AK. Stem cell therapy for cardiac repair: benefits and barriers. Expert Rev Mol Med. 2009;11:e20.

105. Murry CE, Keller G. Differentiation of embryonic stem cells to clinically relevant populations: lessons from embryonic development. Cell. 2008;132:661-680.
106. Kehat I, Kenyagin-Karsenti D, Snir M, et al. Human embryonic stem cells can differentiate into myocytes with structural and functional properties of cardiomyocytes. J Clin Invest. 2001;108:407-414.

107. Laflamme MA, Gold J, Xu C, et al. Formation of human myocardium in the rat heart from human embryonic stem cells. Am J Pathol. 2005;167: 663-671.

108. Behfar A, Perez-Terzic C, Faustino RS, et al. Cardiopoietic programming of embryonic stem cells for tumor-free heart repair. J Exp Med. 2007;204:405-420.

109. Klug MG, Soonpaa MH, Koh GY, Field LJ. Genetically selected cardiomyocytes from differentiating embryonic stem cells form stable intracardiac grafts. J Clin Invest. 1996;98:216-224.

110. Alperin C, Zandstra PW, Woodhouse KA. Polyurethane films seeded with embryonic stem cell-derived cardiomyocytes for use in cardiac tissue engineering applications. Biomaterials. 2005;26:7377-7386.

111. Behfar A, Zingman LV, Hodgson DM, et al. Stem cell differentiation requires a paracrine pathway in the heart. FASEB J. 2002;16: 1558-1566.

112. Behfar A, Hodgson DM, Zingman LV, Perez-Terzic C, Yamada S, Kane GC. Stem Cell Biology: Development and Plasticity. New York, NY: New York Academic Sciences; 2005.

113. Menard C, Hagege AA, Agbulut O, et al. Transplantation of cardiac-committed mouse embryonic stem cells to infarcted sheep myocardium: a preclinical study. Lancet. 2005;366:1005-1012.

114. Menard C, Grey C, Mery A, Zeineddine D, Aimond F, Puceat M. Cardiac specification of embryonic stem cells. J Cell Biochem. 2004; 93:681-687.

115. Swijnenburg RJ, Tanaka M, Vogel H, et al. Embryonic stem cell immunogenicity increases upon differentiation after transplantation into ischemic myocardium. Circulation. 2005;112:I166-I172.

116. Nussbaum J, Minami E, Laflamme MA, et al. Transplantation of undifferentiated murine embryonic stem cells in the heart: teratoma formation and immune response. FASEB J. 2007;21:1345-1357.

117. Segers VF, Lee RT. Stem-cell therapy for cardiac disease. Nature. 2008;451:937-942.

118. Huber I, Itzhaki I, Caspi O, et al. Identification and selection of cardiomyocytes during human embryonic stem cell differentiation. FASEB J. 2007;21:2551-2563.

119. Tomescot A, Leschik J, Bellamy V, et al. Differentiation in vivo of cardiac committed human embryonic stem cells in postmyocardial infarcted rats. Stem Cells. 2007;25:2200-2205.

120. Takahashi K, Tanabe K, Ohnuki M, et al. Induction of pluripotent stem cells from adult human fibroblasts by defined factors. Cell. 2007;131:861-872

121. Yu J, Vodyanik MA, Smuga-Otto K, et al. Induced pluripotent stem cell lines derived from human somatic cells. Science. 2007;318: 1917-1920.

122. Chin MH, Mason MJ, Xie W, et al. Induced pluripotent stem cells and embryonic stem cells are distinguished by gene expression signatures. Cell Stem Cell. 2009;5:111-123.

123. Zhang J, Wilson GF, Soerens AG, et al. Functional cardiomyocytes derived from human induced pluripotent stem cells. Circ Res. 2009; 104:e30-e41.

124. Yu J, Hu K, Smuga-Otto K, et al. Human induced pluripotent stem cells free of vector and transgene sequences. Science. 2009;324: 797-801

125. Beltrami CA, Finatom N, Rocco M, et al. Structural basis of endstage failure in ischemic cardiomyopathy in humans. Circulation. 1994;89:151-163.

126. Gepstein L. Derivation and potential applications of human embryonic stem cells. Circ Res. 2002;91:866-876.

127. Rubart M, Pasumarthi KB, Nakajima H, Soonpaa MH, Nakajima HO, Field LJ. Physiological coupling of donor and host cardiomyocytes after cellular transplantation. Circ Res. 2003;92:1217-1224.

128. Reinecke H, Zhang M, Bartosek T, Murry CE. Survival, integration, and differentiation of cardiomyocyte grafts: a study in normal and injured rat hearts. Circulation. 1999;100:193-202. 
129. Soonpaa MH, Koh GY, Klug MG, Field LJ. Formation of nascent intercalated disks between grafted fetal cardiomyocytes and host myocardium. Science. 1994;264:98-101.

130. Li RK, Mickle DAG, Weisel RD, et al. In vivo survival and function of transplanted rat cardiomyocytes. Circulation. 1997;96:179-187.

131. Etzion S, Battler A, Barbash IM, et al. Influence of embryonic cardiomyocyte transplantation on the progression of heart failure in a rat model of extensive myocardial infarction. J Mol Cell Cardiol. 2001;33: 1321-1330.

132. Taylor DA, Hruban R, Rodriguez ER, Goldschmidt-Clermont PJ. Cardiac chimerism as a mechanism for self-repair: does it happen and if so to what degree? Circulation. 2002;106:2-4

133. Hocht-Zeisberg E, Kahnert H, Guan K, et al. Cellular repopulation of myocardial infarction in patients with sex-mismatched heart transplantation. Eur Heart J. 2004;25:749-758.

134. Li R, Weisel RD, Mickle DAG, et al. Autologous porcine heart cell transplantation improved heart function after a myocardial infarction. J Thorac Cardiovasc Surg. 2000;119:62-68.

135. Pasumarthi KB, Field LJ. Cardiomyocyte cell cycle regulation. Circ Res. 2002;90:1044-1054.

136. Marelli D, Ma F, Chiu RC. Satellite cell implantation for neomyocardial regeneration. Transplant Proc. 1992;24:2995.

137. Taylor DA, Atkins BZ, Hungspreugs P, et al. Regenerating functional myocardium: improved performance after skeletal myoblast transplantation. Nat Med. 1998;4:929-933.

138. Pouly J, Hagege AA, Vilquin JT, et al. Does the functional efficacy of skeletal myoblast transplantation extend to nonischemic cardiomyopathy? Circulation. 2004;110:1626-1631.

139. Tambara K, Sakakibara Y, Sakaguchi G, et al. Transplanted skeletal myoblasts can fully replace the infarcted myocardium when they survive in the host in large numbers. Circulation. 2003;108:II259-II263.

140. Menasché P, Hagége AA, Scorsin M, et al. Myoblast transplantation for heart failure. Lancet. 2001;357:279-280.

141. Reinecke H, Minami E, Poppa V, Murry CE. Evidence for fusion between cardiac and skeletal muscle cells. Circ Res. 2004;94: e56-e60.

142. Leobon B. Myoblasts transplanted into rat infarcted myocardium are functionally isolated from their host. Proc Natl Acad Sci USA. 2003;100:7808-7811.

143. Reinecke H, MacDonald GH, Hauschka SD, Murry CE. Electromechanical coupling between skeletal and cardiac muscle. Implications for infarct repair. J Cell Biol. 2000;149:731-740.

144. Gulati R, Jevremovic D, Peterson TE, et al. Diverse origin and function of cells with endothelial phenotype obtained from adult human blood. Circ Res. 2003;93:1023-1025.

145. Hristov M, Erl W, Weber PC. Endothelial progenitor cells: mobilization, differentiation, and homing. Arterioscler Thromb Vasc Biol. 2003;23:1185-1189.

146. Hill JM, Zalos G, Halcox JP, et al. Circulating endothelial progenitor cells, vascular function, and cardiovascular risk. $N$ Engl J Med. 2003;348:593-600.

147. Urbich C, Heeschen C, Aicher A, Dernbach E, Zeiher AM, Dimmeler S. Relevance of monocytic features for neovascularization capacity of circulating endothelial progenitor cells. Circulation. 2003; 108:2511-2516.

148. Michaud SE, Dussault S, Haddad P, Groleau J, Rivard A. Circulating endothelial progenitor cells from healthy smokers exhibit impaired functional activities. Atherosclerosis. 2006;187:423-432.

149. Vasa M, Fichtlscherer S, Aicher A, et al. Number and migratory activity of circulating endothelial progenitor cells inversely correlate with risk factors for coronary artery disease. Circ Res. 2001;89:E1-E7.

150. Ingram DA, Mead LE, Tanaka $\mathrm{H}$, et al. Identification of a novel hierarchy of endothelial progenitor cells using human peripheral and umbilical cord blood. Blood. 2004;104:2752-2760.

151. Berry MF, Engler AJ, Woo YJ, et al. Mesenchymal stem cell injection after myocardial infarction improves myocardial compliance. Am J Physiol Heart Circ Physiol. 2006;290:H2196-H2203.
152. Grinnemo KH, Mansson-Broberg A, Leblanc K, et al. Human mesenchymal stem cells do not differentiate into cardiomyocytes in a cardiac ischemic xenomodel. Ann Med. 2006;38:144-153.

153. Fukuda K. Regeneration of cardiomyocytes from bone marrow: use of mesenchymal stem cell for cardiovascular tissue engineering. Cytotechnology. 2003;41:165-175.

154. Bartunek J, Croissant JD, Wijns W, et al. Pretreatment of adult bone marrow mesenchymal stem cells with cardiomyogenic growth factors and repair of the chronically infarcted myocardium. Am J Physiol Heart Circ Physiol. 2007;292:H1095-H1104.

155. Genovese JA, Spadaccio C, Chachques E, et al. Cardiac predifferentiation of human mesenchymal stem cells by electrostimulation. Front Biosci. 2009; 14:2996-3002.

156. Toma C, Pittenger MF, Cahill KS, Byrne BJ, Kessler PD. Human mesenchymal stem cells differentiate to a cardiomyocyte phenotype in the adult murine heart. Circulation. 2002;105:93-98.

157. Tomita S, Li RK, Weisel RD, et al. Autologous transplantation of bone marrow cells improves damaged heart function. Circulation. 1999;100:II247-II256

158. Alvarez-Dolado M, Pardal R, Garcia-Verdugo JM, et al. Fusion of bone marrow-derived cells with Purkinje neurons, cardiomyocytes and hepatocytes. Nature. 2003;425:968-973.

159. Yoon YS, Wecker A, Heyd L, et al. Clonally expanded novel multipotent stem cells from human bone marrow regenerate myocardium after myocardial infarction. J Clin Invest. 2005;115:326-338.

160. Katritsis DG, Sotiropoulou P, Giazitzoglou E, Karvouni E, Papamichail M. Electrophysiological effects of intracoronary transplantation of autologous mesenchymal and endothelial progenitor cells. Europace. 2007;9:167-171.

161. Chachques JC, Trainini JC, Lago N, Cortes-Morichetti M, Schussler O, Carpentier A. Myocardial Assistance by Grafting a New Bioartificial Upgraded Myocardium (MAGNUM trial): clinical feasibility study. Ann Thorac Surg. 2008;85:901-908.

162. Perin EC, Dohmann HF, Borojevic R, et al. Transendocardial, autologous bone marrow cell transplantation for severe, chronic ischemic heart failure. Circulation. 2003;107:2294-2302.

163. Dib N, Diethrich EB, Campbell A, et al. Endoventricular transplantation of allogenic skeletal myoblasts in a porcine model of myocardial infarction. J Endovasc Ther. 2002;9:313-319.

164. Davis ME, Hsieh PC, Grodzinsky AJ, Lee RT. Custom design of the cardiac microenvironment with biomaterials. Cir Res. 2005;97: 8-15.

165. Dai W, Wold LE, Dow JS, Kloner RA. Thickening of the infarcted wall by collagen injection improves left ventricular function in rats: a novel approach to preserve cardiac function after myocardial infarction. J Am Coll Cardiol. 2005;46:714-719.

166. Christman KL, Fok HH, Sievers RE, Fang Q, Lee RJ. Fibrin glue alone and skeletal myoblasts in a fibrin scaffold preserve cardiac function after myocardial infarction. Tissue Eng. 2004;10:403-409.

167. Stevens MM, George JH. Exploring and engineering the cell surface interface. Science. 2005;310:1135-1138.

168. Leor J, Tuvia S, Guetta V, et al. Intracoronary injection of in situ forming alginate hydrogel reverses left ventricular remodeling after myocardial infarction in swine. J Am Coll Cardiol. 2009;54:1014-1023.

169. Koh CJ, Atala A. Tissue engineering, stem cells, and cloning: opportunities for regenerative medicine. J Am Soc Nephrol. 2004;15: 1113-1125.

170. Landa N, Miller L, Feinberg MS, et al. Effect of injectable alginate implant on cardiac remodeling and function after recent and old infarcts in rat. Circulation. 2008;117:1388-1396.

171. Hao X, Silva EA, Mansson-Broberg A, et al. Angiogenic effects of sequential release of VEGF-A165 and PDGF-BB with alginate hydrogels after myocardial infarction. Cardiovasc Res. 2007;75:178-185.

172. Yu J, Gu Y, Du KT, Mihardja S, Sievers RE, Lee RJ. The effect of injected RGD modified alginate on angiogenesis and left ventricular function in a chronic rat infarct model. Biomaterials. 2009;30: $751-756$. 
173. Mihardja SS, Sievers RE, Lee RJ. The effect of polypyrrole on arteriogenesis in an acute rat infarct model. Biomaterials. 2008;29: 4205-4210.

174. Garner B, Georgevich A, Hodgson AJ, Liu L, Wallace GG. Polypyrrole-heparin composites as stimulus-responsive substrates for endothelial cell growth. J Biomed Mater Res. 1999;44:121-129.

175. Lee KY, Mooney DJ. Hydrogels for tissue engineering. Chem Rev. 2001;101:1869-1879.

176. Ahmed TA, Dare EV, Hincke M. Fibrin: a versatile scaffold for tissue engineering applications. Tissue Eng Part B Rev. 2008;14:199-215.

177. Sierra DH. Fibrin sealant adhesive systems: a review of their chemistry, material properties and clinical applications. J Biomater Appl. 1993; 7: 309-352.

178. Christman KL, Vardanian AJ, Fang Q, Sievers RE, Fok HH, Lee RJ. Injectable fibrin scaffold improves cell transplant survival, reduces infarct expansion, and induces neovasculature formation in ischemic myocardium. J Am Coll Cardiol. 2004;44:654-660.

179. Yu J, Christman KL, Chin E, Sievers RE, Saeed M, Lee RJ. Restoration of left ventricular geometry and improvement of left ventricular function in a rodent model of chronic ischemic cardiomyopathy. JThorac Cardiovasc Surg. 2009;137:180-187.

180. Ryu JH, Kim IK, Cho SW, et al. Implantation of bone marrow mononuclear cells using injectable fibrin matrix enhances neovascularization in infarcted myocardium. Biomaterials. 2005;26:319-326.

181. Singelyn JM, Christman KL. Injectable materials for the treatment of myocardial infarction and heart failure: the promise of decellularized matrices. J Cardiovasc Trans Res. 2010;3:478-486.

182. Khor E, Lim LY. Implantable applications of chitin and chitosan. Biomaterials. 2003;24:2339-2249.

183. Lu WN, Lu SH, Wang HB, et al. Functional improvement of infarcted heart by co-injection of embryonic stem cells with temperatureresponsive chitosan hydrogel. Tissue Eng Part A. 2009;15:1437-1447.

184. Chenite A, Chaput C, Wang D, et al. Novel injectable neutral solutions of chitosan form biodegradable gels in situ. Biomaterials. 2000;21: 2155-2161.

185. Yeo Y, Geng W, Ito T, Kohane DS, Burdick JA, Radisic M. Photocrosslinkable hydrogel for myocyte cell culture and injection. J Biomed Mater Res B Appl Biomater. 2007;81:312-322.

186. Maeda M, Tani S, Sano A, Fujioka K. Microstructure and release characteristics of the minipellet, a collagen-based drug delivery system for controlled release of protein drugs. J Control Release. 1999;62: 313-324.

187. Kutschka I, Chen IY, Kofidis T, et al. Collagen matrices enhance survival of transplanted cardiomyoblasts and contribute to functional improvement of ischemic rat hearts. Circulation. 2006;114:I167-I173.

188. Kutschka I, Chen IY, Kofidis T, et al. In vivo optical bioluminescence imaging of collagen-supported cardiac cell grafts. J Heart Lung Transplant. 2007;3:273-280.

189. Zhang Y, Thorn S, DaSilva JN, et al. Collagen-based matrices improve the delivery of transplanted circulating progenitor cells: development and demonstration by ex vivo radionuclide cell labeling and in vivo tracking with positron-emission tomography. Circ Cardiovasc Imaging. 2008;3:197-204.

190. Nelson DM, Ma Z, Fujimoto KL, Hashizume R, Wagner WR. Intra-myocardial biomaterial injection therapy in the treatment of heart failure: materials, outcomes and challenges. Acta Biomater. 2011;7: $1-15$.

191. Huang NF, Yu J, Sievers R, Li S, Lee RJ. Injectable biopolymers enhance angiogenesis after myocardial infarction. Tissue Eng. 2005; 11:1860-1866.

192. Kofidis T, de Bruin JL, Hoyt G, et al. Injectable bioartificial myocardial tissue for large-scale intramural cell transfer and functional recovery of injured heart muscle. J Thorac Cardiovasc Surg. 2004;128:571-578.

193. Kofidis T, Lebl DR, Martinez EC, Hoyt G, Tanaka M, Robbins RC. Novel injectable bioartificial tissue facilitates targeted, less invasive, large-scale tissue restoration on the beating heart after myocardial injury. Circulation. 2005;112:I173-I177.
194. Albini A, Melchiori A, Garofalo A, et al. Matrigel promotes retinoblastoma cell growth in vitro and in vivo. Int J Cancer. 1992;52: 234-240.

195. Davis ME, Motion JP, Narmoneva DA, et al. Injectable self assembling peptide nanofibers create intramyocardial microenvironments for endothelial cells. Circulation. 2005;111:442-450.

196. Gilbert TW, Sellaro TL, Badylak SF. Decellularization of tissues and organs. Biomaterials. 2006;27:3675-3683.

197. Singelyn JM, DeQuach JA, Seif-Naraghi SB, Littlefield RB, SchupMagoffin PJ, Christman KL. Naturally derived myocardial matrix as an injectable scaffold for cardiac tissue engineering. Biomaterials. 2009;30:5409-5416.

198. Seif-Naraghi SB, Salvatore MA, Schup-Magoffin PJ, Hu DP, Christman KL. Design and characterization of an injectable pericardial matrix gel: a potentially autologous scaffold for cardiac tissue engineering. Tissue Eng Part A. 2010;16:2017-2027.

199. Badylak SF. The extracellular matrix as a biologic scaffold material. Biomaterials. 2007;28:3587-3593.

200. Ott HC, Matthiesen TS, Goh SK, et al. Perfusion decellularized matrix: using nature's platform to engineer a bioartificial heart. Nat Med. 2008;14:213-221.

201. Zhao ZQ, Puskas JD, Xu D, et al. Improvement in cardiac function with small intestine extracellular matrix is associated with recruitment of C-kit cells, myofibroblasts, and macrophages after myocardial infarction. J Am Coll Cardiol. 2010;55:1250-1261.

202. Badylak SF, Obermiller J, Geddes L, Matheny R. Extracellular matrix for myocardial repair. Heart Surg Forum. 2002;6:E20-E26.

203. Mukherjee R, Zavadzkas JA, Saunders SM, et al. Targeted myocardial microinjection of a biocomposite material reduces infarct expansion in pigs. Ann Thorac Surg. 2008;86:1268-1276.

204. Zhang G, Hu Q, Braunlin EA, Suggs LJ, Zhang J. Enhancing efficacy of stem cell transplantation to the heart with a PEGylated fibrin biomatrix. Tissue Eng Part A. 2008;14:1025-1036.

205. Narmoneva DA, Vukmirovic R, Davis ME, Kamm RD, Lee RT. Endothelial cells promote cardiac myocyte survival and spatial reorganization: implications for cardiac regeneration. Circulation. 2004;110:962-968

206. Holmes TC. Novel peptide-based biomaterial scaffolds for tissue engineering. Trends Biotechnol. 2002;20:16-21.

207. Hsieh PC, MacGillivray C, Gannon J, Cruz FU, Lee RT. Local controlled intramyocardial delivery of platelet-derived growth factor improves postinfarction ventricular function without pulmonary toxicity. Circulation. 2006;114:637-644.

208. Hsieh PC, Davis ME, Gannon J, MacGillivray C, Lee RT. Controlled delivery of PDGF-BB for myocardial protection using injectable self-assembling peptide nanofibers. $J$ Clin Invest. 2006;116: 237-248.

209. Segers VF, Tokunou T, Higgins LJ, MacGillivray C, Gannon J, Lee RT. Local delivery of protease-resistant stromal cell derived factor-1 for stem cell recruitment after myocardial infarction. Circulation. 2007;116:1683-1692.

210. Dobner S, Bezuidenhout D, Govender P, Zilla P, Davies N. A synthetic non-degradable polyethylene glycol hydrogel retards adverse post-infarct left ventricular remodeling. J Card Fail. 2009; 15:629-636.

211. Fujimoto KL, Ma Z, Nelson DM, et al. Synthesis, characterization and therapeutic efficacy of a biodegradable, thermoresponsive hydrogel designed for application in chronic infarcted myocardium. Biomaterials. 2009;30:4357-4368.

212. Purcell BP, Elser JA, Mu A, Margulies KB, Burdick JA. Synergistic effects of SDF- $1 \alpha$ chemokine and hyaluronic acid release from degradable hydrogels on directing bone marrow derived cell homing to the myocardium. Biomaterials. 2012;33:7849-7857.

213. Chi NH, Yang MC, Chung TW, Chen JY, Chou NK, Wang SS Cardiac repair achieved by bone marrow mesenchymal stem cells/ silk fibroin/hyaluronic acid patches in a rat of myocardial infarction model. Biomaterials. 2012;33:5541-5551. 
214. Wang H, Liu Z, Li D, et al. Injectable biodegradable hydrogels for embryonic stem cell transplantation: improved cardiac remodelling and function of myocardial infarction. J Cell Mol Med. 2012;16: $1310-1320$.

215. Davis ME, Hsieh PC, Takahashi T, et al. Local myocardial insulin-like growth factor 1 (IGF-1) delivery with biotinylated peptide nanofibers improves cell therapy for myocardial infarction. Proc Natl Acad Sci US A. 2006;103:8155-8160.

216. Padin-Iruegas ME, Misao Y, Davis ME, et al. Cardiac progenitor cells and biotinylated insulin-like growth factor-1 nanofibers improve endogenous and exogenous myocardial regeneration after infarction. Circulation. 2009;120:876-887.

217. Kawada H, Fujita J, Kinjo K, et al. Nonhematopoietic mesenchymal stem cells can be mobilized and differentiate into cardiomyocytes after myocardial infarction. Blood. 2004;104:3581-3587.

218. Ohtsuka M, Takano H, Zou Y, et al. Cytokine therapy prevents left ventricular remodeling and dysfunction after myocardial infarction through neovascularization. FASEB J. 2004;18:851-853.

219. Casilde S, Sharon LH, Carolyn L, Robert AK. Granulocyte colonystimulating factor and stem cell factor improve contractile reserve of the infarcted left ventricle independent of restoring muscle mass. J Am Coll Cardiol. 2005;46:1662-1669.

220. Lee KY, Peters MC, Anderson KW, Mooney DJ. Controlled growth factor release from synthetic extracellular matrices. Nature. 2000;408: 998-1000.

221. Iwakura A, Fujita M, Kataoka K, et al. Intramyocardial sustained delivery of basic fibroblast growth factor improves angiogenesis and ventricular function in a rat infarct model. Heart Vessels. 2003;18: 93-99.

222. Christman KL, Fang Q, Yee MS, Johnson KR, Sievers RE, Lee RJ. Enhanced neovasculature formation in ischemic myocardium following delivery of pleiotrophin plasmid in a biopolymer. Biomaterials. 2005;26:1139-1144
223. Perets A, Baruch Y, Weisbuch F, Shoshany G, Neufeld G, Cohen S. Enhancing the vascularization of three-dimensional porous alginate scaffolds by incorporating controlled release basic fibroblast growth factor microspheres. J Biomed Mater Res. 2003;65A:489-497.

224. Urech L, Bittermann AG, Hubbell JA, Hall H. Mechanical properties, proteolytic degradability and biological modifications affect angiogenic process extension into native and modified fibrin matrices in vitro. Biomaterials. 2005;26:1369-1379.

225. Semler EJ, Ranucci CS, Moghe PV. Mechanochemical manipulation of hepatocyte aggregation can selectively induce or repress liver-specific function. Biotechnol Bioeng. 2000;69:359-369.

226. Barocas VH, Moon AG, Tranquillo RT. The fibroblast populated microsphere assay of cell traction force - part 2: measurement of the cell traction coefficient. J Biomech Eng. 1995;117:161-170.

227. Stile RA, Chung E, Burghardt WR, Healy KE. Poly(Nisopropylacrylamide)-based semi-interpenetrating polymer networks for tissue engineering applications. Effects of linear poly(acrylic acid) chains on rheology. J Biomater Sci Polym Ed. 2004;15:865-878.

228. Kim S, Healy KE. Synthesis and characterization of injectable poly(Nisopropylacrylamideco-acrylic acid) hydrogels with proteolytically degradable cross-links. Biomacromolecules. 2003;4:1214-1223.

229. Stokke BT, Draget KI, Smidsrod O, Yuguchi Y, Urakawa H, Kajiwara K. Small-angle X-ray scattering and rheological characterization of alginate gels. 1. Ca-alginate gels. Macromolecules. 2000;33: 1853-1863.

230. Rizzi SC, Ehrbar M, Halstenberg S, et al. Recombinant protein-co-PEG networks as cell-adhesive and proteolytically degradable hydrogel matrixes part II: biofunctional characteristics. Biomacromolecules. 2006; 7:3019-3029.

231. Omens JH. Stress and strain as regulators of myocardial growth. Prog Biophys Mol Biol. 1998;69:559-572.

232. Eschenhagen T, Didie M, Heubach J, Ravens U, Zimmermann WH. Cardiac tissue engineering. Transpl Immunol. 2002;9:315-321.
International Journal of Nanomedicine

\section{Publish your work in this journal}

The International Journal of Nanomedicine is an international, peerreviewed journal focusing on the application of nanotechnology in diagnostics, therapeutics, and drug delivery systems throughout the biomedical field. This journal is indexed on PubMed Central, MedLine, CAS, SciSearch $\AA$, Current Contents ${ }^{\circledR} /$ Clinical Medicine,

\section{Dovepress}

Journal Citation Reports/Science Edition, EMBase, Scopus and the Elsevier Bibliographic databases. The manuscript management system is completely online and includes a very quick and fair peer-review system, which is all easy to use. Visit http://www.dovepress.com/ testimonials.php to read real quotes from published authors. 